\title{
Oncolytic virotherapy for ovarian cancer
}

This article was published in the following Dove Press journal:

Oncolytic Virotherapy

22 August 2012

Number of times this article has been viewed

\author{
Shoudong $\mathrm{Li}^{\prime}$ \\ Jessica Tong ${ }^{2,3}$ \\ Masmudur M Rahman' \\ Trevor G Shepherd ${ }^{2,3}$ \\ Grant McFadden' \\ 'Department of Molecular Genetics \\ and Microbiology, University \\ of Florida, Gainesville, FL, USA; \\ ${ }^{2}$ Department of Anatomy and Cell \\ Biology, University of Western \\ Ontario, London, Ontario, Canada; \\ ${ }^{3}$ Translational Ovarian Cancer \\ Research Program, London Health \\ Sciences Centre, London, Ontario, \\ Canada
}

Correspondence: Grant McFadden Department of Molecular Genetics and Microbiology, University of Florida, 1600 SW Archer Rd, PO Box 100266 , Gainesville, FL 3260I0, USA

Tel +I 3522736852

Fax + I 3522736849

Email grantmcf@ufl.edu

Trevor G Shepherd

Cancer Research Laboratory Program, London Regional Cancer Program,

790 Commissioners Road East,

Room A4-836, London, Ontario,

Canada N6A 4L6

$\mathrm{Tel}+\mathrm{I} 5196858500$ ext 56347

Fax +I 5196858673

Email tshephe6@uwo.ca
Abstract: In the past two decades, more than 20 viruses with selective tropism for tumor cells have been developed as oncolytic viruses (OVs) for treatments of a variety of malignancies. Of these viruses, eleven have been tested in human ovarian cancer models in preclinical studies. So far, nine phase I or II clinical trials have been conducted or initiated using four different types of OVs in patients with recurrent ovarian cancers. In this article, we summarize the different OVs that are being assessed as therapeutics for ovarian cancer. We also present an overview of recent advances in identification of key genetic or immune-response pathways involved in tumorigenesis of ovarian cancer, which provides a better understanding of the tumor specificities and oncolytic properties of OVs. In addition, we discuss how next-generation OVs could be genetically modified or integrated into multimodality regimens to improve clinical outcomes based on recent advances in ovarian cancer biology.

Keywords: oncolytic virus, virotherapy, ovarian cancer, preclinical studies, clinical trial

\section{Introduction}

Ovarian cancer is the sixth most prevalent cancer in women and the most lethal of the gynecologic malignancies. ${ }^{1,2}$ If caught at an early stage, the majority (approximately 90\%) of ovarian cancer patients are cured. Approximately $90 \%$ of ovarian tumors are epithelial in origin, with the remainder being sex cord-stromal and germ cell tumors. These latter, rarer tumor types of the ovary and epithelial tumors that are confined to one or both ovaries (ie, stage 1A/B) are usually treated with surgery alone due to the early diagnosis and lower metastatic potential. Over three-quarters of ovarian tumors, however, are discovered at an advanced metastatic stage, when prognosis is poor.

Most other carcinomas follow a pathway of disease dissemination that involves intravasation into the bloodstream followed by extravasation at distant tissue sites, as well involvement of lymphatic spread. ${ }^{3}$ Metastasis of epithelial ovarian cancer is unique in that it typically spreads by direct dissemination or shedding of cancer cells from the primary tumor site into the ascites of the peritoneal space, followed by secondary tumor seeding by implantation onto the serosal surfaces of abdominal organs. ${ }^{4,5}$ This implies that there are likely molecular and cellular properties of ovarian tumor cells that dictate this pattern of metastasis; unique properties, perhaps, that could be exploited for more efficacious therapeutic strategies.

\section{Heterogeneity of ovarian cancer}

Epithelial ovarian cancer does not represent a single disease, but rather can be distinguished and characterized as distinct histological subtypes. ${ }^{6}$ The four most 
common histotypes of epithelial ovarian cancer are serous, endometrioid, clear cell, and mucinous; these can also be subclassified based on grade, although clear cell is always considered high-grade. Further to this complexity, a substantial proportion of epithelial ovarian cancer cases will be of mixed histologies.

Over the last several years, genetics, genomics, and gene-expression analyses have demonstrated that there are common mutations and aberrant signaling pathways that typify these histologic subtypes. High-grade serous ovarian cancers almost universally harbor mutations in TP53, and these tumor cells are defined as being highly genomically unstable. ${ }^{7,8}$ In comparison, TP53 mutations and genomic instability are rare in low-grade serous ovarian cancers, but rather these tumor types commonly possess activating mutations in $K R A S$ and $B R A F$. Gene-expression analyses have corroborated clinicopathologic definitions of these histologic subtypes, since each subtype has a characteristic gene-expression pattern resembling the normal cell/tissue type. ${ }^{9}$ Serous ovarian cancer is similar to fallopian tube epithelium, endometrioid, and clear cell to endometrial cells, and mucinous to gastrointestinal cells of the colon. This also reflects the argument that a subset of these ovarian malignancies may arise from origins alternative to the ovary. For example, a substantial amount of strong evidence directs the putative source of high-grade serous ovarian cancer in the secretory epithelial cells of fallopian tube fimbriae. ${ }^{10}$ Endometriosis, a common pathologic condition seen in approximately $15 \%$ of all women, is also a potential source for endometrioid and clear cell cancers of the ovary. ${ }^{11}$ This heterogeneity in tumor types seen in epithelial ovarian cancer is clinically relevant, since it is well established that tumor aggressiveness, response to chemotherapy, and patient prognosis are correlated with tumor type. ${ }^{2}$ There is a trend towards rationally selecting patients for clinical trials using targeted therapeutics based on ovarian cancer histologic subtype ${ }^{12}$ however, the majority of ovarian cancer patients with metastatic disease are treated with the standard regimen of combined carboplatin and paclitaxel. It remains to be seen if ovarian cancer will be a cancer type that can reap further benefits of personalized medicine through the targeting of histologic subtypes with their underlying genetic and biochemical defects.

\section{Ovarian cancer-initiating cells}

The cancer-initiating cell (CIC) theory maintains that a minority of cells within a primary tumor have the unique capacity to repopulate a heterogeneous tumor as well as self-renew. ${ }^{13}$ CICs are believed to commonly have a low mitotic rate as well as express factors that can promote their survival. Given this, CICs demonstrate resistance to chemoand radiotherapy, thus serving as a potential source for cancer recurrence, since current chemotherapies commonly fail to eliminate CICs. ${ }^{14} \mathrm{CICs}$ were originally defined within hematologic malignancies, but they have been identified in many different solid cancers over the past decade, including breast, ${ }^{15}$ prostate, ${ }^{16}$ colon, ${ }^{17,18}$ liver, ${ }^{19}$ pancreatic,${ }^{20}$ brain, ${ }^{21}$ melanoma, ${ }^{22}$ and ovarian. ${ }^{23-25}$

Ovarian CICs (OCICs) have been identified by several groups and have been isolated and characterized using a diverse set of markers and activities. Szotek and colleagues successfully isolated OCICs in mouse ovarian tumor cells and from human ovarian cancer cell lines and patient ascites by verapamil-sensitive Hoechst efflux side population (SP). ${ }^{24}$ Fitting the definition of CICs, the SP cells represented $<1 \%$ of the origin population of cells, had more robust sphereforming and tumour-forming potential than non-SP cells, and repopulated a heterogeneous tumor of both SP and non-SP cells. Subsequent to this first report, other groups have selected OCICs from human ovarian tumors by sorting for cell surface coexpression of $\mathrm{CD} 44^{+}$and $\mathrm{CD} 117^{+},{ }^{25} \mathrm{CD} 44^{+}$and $\mathrm{MyD}^{+} 8^{+}{ }^{26}$ or $\mathrm{CD} 133^{+}$and $\mathrm{CD} 117^{+},{ }^{27}$ although enrichment for stem-like cells has also been performed using $\mathrm{CD} 133^{+28,29}$ or $\mathrm{CD} 24^{+30}$ alone. More recently, groups have demonstrated that aldehyde dehydrogenase activity can define an OCIC population in combination with CD133 31,32 or CD $44 .{ }^{33}$ A recent study tested 150 combinations of eight cancer stem cell markers and found that the combination of three-CD44, CD24, and epithelial cell adhesion molecule-exhibited the most robust enrichment of OCICs. ${ }^{34}$ Importantly, the OCICs that have been identified by these different methods are commonly less sensitive to standard chemotherapeutics used to treat ovarian cancer patients. ${ }^{26}$ Thus, if these cells are the main contributors to recurrence of resistant disease, then therapeutics that are more efficacious at targeting and killing these progenitor cells are of utmost importance.

\section{Immune response in ovarian cancer}

It is important to recognize and appreciate the antitumor immune response and subsequent immune evasion by late-stage metastatic cancers as a universal hallmark of malignancy. ${ }^{35,36}$ The immune system is thought to play an essential role in facilitating tumor regression in response to chemotherapy for ovarian cancer. The presence of tumorinfiltrating lymphocytes in response to chemotherapy and even before chemotherapy is initiated is associated with 
better prognosis for ovarian cancer patients. ${ }^{37,38}$ There have been numerous activities to generate anticancer vaccines for ovarian cancer, ${ }^{39}$ yet none have come to fruition. Interestingly, a recent report has targeted OCICs via fusion with dendritic cells as being a potential means for immunotherapy for ovarian cancer. ${ }^{40,41}$

Late-stage ovarian tumors are believed to grow in an immunosuppressive environment, with many key cytokines known to stimulate an antitumor response being significantly reduced in the hostile ascites environment during metastatic disease progression. ${ }^{42}$ For example, transforming growth factor-beta, which is a potent immunosuppressive factor known to promote late-stage human cancer progression, ${ }^{43}$ is present in biologically relevant quantities in malignant ascites. ${ }^{44,45}$ Taken together, it implies that recruiting an active immune response is likely a critical component to effective therapy for ovarian cancer; however, significant pathobiological hurdles would still have to be overcome.

\section{Preclinical studies with oncolytic viruses in ovarian cancer}

Debulking surgery followed by chemotherapy using a platinum/taxane-based regimen is the current standard of care for ovarian cancer. However, more than $65 \%$ of patients will eventually relapse. ${ }^{46}$ The overall 5 -year survival rate for all stages of ovarian cancer is currently less than $50 \%$, and for advanced ovarian cancer remains $15 \%-30 \% .^{1}$ New, more effective therapeutic approaches for treatment of recurrent or drug-resistant ovarian cancer remain an urgent unmet medical need. The emerging oncolytic virotherapy represents a unique strategy and holds great promise for cancer therapy. Oncolytic virotherapy is defined as the use of a class of nonor low-pathogenic viruses that is able to preferably replicate in cancer cells and eliminate them in situ; for example, via direct lysis or induction of apoptosis. ${ }^{47}$ Currently exploited oncolytic viruses (OVs) are either naturally occurring viruses (either human or nonhuman) that have little or no natural pathogenicity in humans, including reovirus, myxoma virus (MYXV), vaccinia virus (VV), measles virus (MV), vesicular stomatitis virus (VSV), sindbis virus (SV), Maraba virus (MRB), and echovirus type 1 (EV1), or comprise genetically engineered viruses, including adenoviruses (Ads), herpes simplex viruses (HSVs) or certain poxviruses. The OVs that are currently being developed to treat ovarian cancer are summarized in Table 1. Most recently, two related reviews on OVs for ovarian cancer have been published, one review outlining the current status of the clinical data from human trials and the other focusing on OVs for gynecologic malignancies. ${ }^{48,49}$ In this review, we attempt to provide more comprehensive and up-to-date summaries of the molecular biology of ovarian cancer and the results from preclinical and clinical studies using OVs for ovarian cancer.

\section{General mechanisms of tumor selectivity of OVs}

The development of malignancies, namely tumorigenesis, can be seen as an evolution of normal cells to acquire the capacity for uncontrolled cell division and invasive capabilities that mediate dissemination into normal organs and tissues. During this process, tumor cells acquire genetic mutations and cellular changes that progressively interfere with tumor cell recognition and clearance by host immune pathways. Coincidentally, these cellular and genetic changes of the tumor cells over normal cells also provide the molecular targets for OVs to selectively infect and replicate in tumor cells. There are at least five general mechanisms that determine the tumor selectivity of OVs.

\section{Defective innate immune responses of tumor cells}

The most important inducible innate antiviral defense system in normal cells is the interferon (IFN) signaling pathway. In normal somatic cells, virus invasion can be sensed by a variety of sentinel receptors, such as membrane-bound Toll-like receptors or cytoplasmic sensors like the nucleic acid helicases encoded by retinoic-acid inducible gene-I, melanoma differentiation associated gene 5, and DNA-dependent activator of IFN regulatory factors. ${ }^{50}$ Viral infections trigger these sensor proteins to initiate signaling cascades that trigger IFN induction and secretion from most nontransformed mammalian cells. Secreted type I IFN then acts on both virus-infected and uninfected cells to upregulate the expression of many antiviral proteins. Over 200 such IFN-inducible host proteins have been described, including members whose primary function is to intercept the virus infection. ${ }^{51}$ One example of such an IFN-induced antiviral protein is protein kinase $\mathrm{R}$ (PKR). Once induced, PKR can then be activated by virus-derived dsRNA. Upon activation, PKR phosphorylates and inactivates eukaryotic initiation factor 2 alpha (eIF2 $\alpha$ ), causing global inhibition of protein synthesis of both host and viral proteins. ${ }^{51}$ IFN also has tumor-suppression properties that are also mediated by PKR and other IFN-stimulated proteins. Genetic defects in the cellular IFN-response pathway, as well as other related innate immune responses (eg, TNF induction, apoptosis, etc) are also frequently seen in cancer cells, and these acquired signaling defects may in fact be crucial for the proliferation and immune evasion of cancer cells. ${ }^{52,53}$ An indirect consequence 
Table I Oncolytic viruses in preclinical studies on ovarian cancer therapy

\begin{tabular}{|c|c|c|c|c|}
\hline Oncolytic virus & Genome and structure & Genetic modification & Tumor selectivity & Refs \\
\hline \multirow[t]{5}{*}{$\begin{array}{l}\text { Adenovirus } \\
\text { (serotype 5) }\end{array}$} & $\begin{array}{l}\text { 36-kb dsDNA } \\
\text { nonenveloped }\end{array}$ & EIB 55-kD deletion & $\begin{array}{l}\text { Aberrant p53 pathway and } \\
\text { aberrant mRNA transport }\end{array}$ & 90,91 \\
\hline & & EIA CR2 deletion & Aberrant Rb pathway & 92,93 \\
\hline & & Tropism modification & $\begin{array}{l}\text { RGD motif insertion targeting } \\
\text { TS integrins }\end{array}$ & 59 \\
\hline & & & Ad5/3 chimeric capsid targeting & 103,104 \\
\hline & & & $\begin{array}{l}\text { TS desmoglein-2 } \\
\text { TSP-driven EIA expression }\end{array}$ & $68,105-107$ \\
\hline \multirow[t]{3}{*}{$\begin{array}{l}\text { Herpes simplex } \\
\text { virus I and } 2\end{array}$} & $\begin{array}{l}\sim 150-k b \text { dsDNA } \\
\text { enveloped }\end{array}$ & $\gamma 34.5$ gene deletion & $\begin{array}{l}\text { Aberrant PKR signaling or } \\
\text { PI3K pathway }\end{array}$ & 120,121 \\
\hline & & ICPIO deletion & Activated Ras-signaling pathway & 127 \\
\hline & & Deletion of viral $R R$ & Upregulation of cellular RR & 130 \\
\hline \multirow[t]{3}{*}{ Vaccinia virus } & 190-kb dsDNA & TK gene deletion & Upregulation of cellular TK & 133 \\
\hline & enveloped & VFG deletion & $\begin{array}{l}\text { Activation of VEGF-signaling } \\
\text { pathway }\end{array}$ & 133 \\
\hline & & Natural attenuation & $\begin{array}{l}\text { Ras-signaling pathway, } \\
\text { defective IFN pathway }\end{array}$ & 136 \\
\hline Myxoma virus & $\begin{array}{l}\text { I60-kb dsDNA } \\
\text { enveloped }\end{array}$ & None & $\begin{array}{l}\text { Defective TNF/IFN pathway, } \\
\text { activated Akt }\end{array}$ & $|4|, \mid 42$ \\
\hline $\begin{array}{l}\text { Reovirus } \\
\text { (serotype 3) }\end{array}$ & $\begin{array}{l}\text { 24-kb dsRNA } \\
\text { nonenveloped }\end{array}$ & None & Activated Ras-signaling pathway & 55 \\
\hline Measles virus & $\begin{array}{l}\text { 16-kb ss(-) RNA } \\
\text { enveloped }\end{array}$ & $\begin{array}{l}\text { Attenuated vaccine } \\
\text { Tropism modification }\end{array}$ & $\begin{array}{l}\text { Targeting TS CD46 receptor } \\
\text { Incorporation of signal-chain } \\
\text { antibody retargeting } \\
\text { TS FR } \alpha \text { receptor }\end{array}$ & $\begin{array}{l}56 \\
60\end{array}$ \\
\hline Mumps virus & $\begin{array}{l}\text { I5-kb ss(-) RNA } \\
\text { enveloped }\end{array}$ & Attenuated vaccine & Likely defective antiviral pathway & 200 \\
\hline VSV & $\begin{array}{l}\text { II-kb ss(-) RNA } \\
\text { enveloped }\end{array}$ & None & Defective IFN pathway & 165 \\
\hline Maraba virus & $\begin{array}{l}\text { II-kb ss(-) RNA } \\
\text { enveloped }\end{array}$ & Attenuated strain & $\begin{array}{l}\text { Defective IFN pathway, and unknown, } \\
\text { IFN- independent defects in cancer cells }\end{array}$ & 174 \\
\hline Sindbis virus & $\begin{array}{l}\text { I2-kb ss(+) RNA } \\
\text { enveloped }\end{array}$ & None & $\begin{array}{l}\text { Targeting TS LAMR, defective } \\
\text { IFN pathway }\end{array}$ & 57,178 \\
\hline Echovirus type I & $\begin{array}{l}\text { 7.5-kb ss }(+) \text { RNA } \\
\text { nonenveloped }\end{array}$ & None & $\begin{array}{l}\text { Targeting TS integrin, defective } \\
\text { IFN pathway }\end{array}$ & 58,201 \\
\hline
\end{tabular}

Abbreviations: TSP, tumor-specific promoter; TS, tumor specific; TK, thymidine kinase; RR, ribonucleotide reductase; VEGF, vascular endothelial growth factor; IFN, interferon; PKR, protein kinase R; TNF, tumor necrosis factor; PI3K, phosphatidylinositol 3-kinase; LAMR, laminin receptor.

of these cellular defects is to frequently convert cancer cells to be more permissive to infection by a spectrum of OVs that are typically more efficiently suppressed in normal somatic cells. For example, one of the common mutations leading to inhibition of the IFN signaling response pathway is constitutive Ras activation caused by various mutations to this cellular oncogene (present in approximately $30 \%$ of all human cancers). ${ }^{54}$ Activated Ras signaling also inhibits PKR, likely through dephosphorylation of PKR, and this in turn promotes infection and oncolysis of Ras-activated cancer cells by reovirus. ${ }^{55}$

\section{Overexpression of viral receptors on tumor cells}

Many cancer-specific mutations result in elevated expression of certain cell surface molecules that facilitate tumorigenesis and/or metastasis. These molecules, often expressed at low levels or absent on normal cells, usually affect adherence or migration of cancer cells, but they can also serve as the cell-entry receptors for OVs. For instance, cancer-specific CD $46,{ }^{56} 67-\mathrm{kD}$ high affinity laminin receptor (LAMR), ${ }^{57}$ and integrin $\alpha_{2} \beta_{1}^{58}$ are utilized by the oncolytic MV Edmonston strain, $\mathrm{SV}$, and EV1, respectively. Additionally, some OVs can be genetically modified to retarget recombinant viruses to cancer-specific receptors such as the integrins $\alpha_{v} \beta_{3}$ and $\alpha_{v} \beta_{5}$, $\alpha$-folate receptor $(\mathrm{FR} \alpha)$, or epidermal growth factor receptor (EGFR) ${ }^{59-62}$ All these cancer-specific surface proteins, for example, can be found on most ovarian cancer cells.

\section{Dysregulation of the tumor cell cycle}

Mutations in tumor suppressor genes, such as $p 53$ and $R b$, may lead to dysregulation of cell cycle and suppression of apoptosis, creating a cellular environment favoring continued 
proliferation of the cancer cells. Some OVs have been engineered by deletion of essential viral genes involved in interaction with cellular proliferation-regulatory proteins in normal cells, thus enabling selective replication of the OVs in tumor cells. For example, VV constructs that have been deleted in the viral thymidine kinase $(T K)$ gene can only replicate efficiently in proliferating cancer cells that highly express cellular TK but less efficiently in normal noncycling cells with a low level of cellular TK. ${ }^{63}$ As another example, deletion mutation of the adenovirus $E 1 A$ gene can preempt $\mathrm{E} 1 \mathrm{~A}$ interaction with $\mathrm{Rb}$ protein and thus restricts the replication of the mutant virus in cancer cells with missing or aberrant $\mathrm{Rb}{ }^{64}$

\section{Tumor-specific promoter-controlled transcription}

Restriction of OV replication in certain cancer cells can also be accomplished by insertion of a tumor cell-responsive tumor-specific promoter (TSP) that drives the expression of viral genes essential for virus replication. TSPs that have been tested in ovarian cancer cells include cyclooxygenase 2 (COX2), vascular endothelial growth factor receptor (VEGF), mesothelin, midkine, survivin, the secretory leukoprotease inhibitor, and the $\mathrm{C}-\mathrm{X}-\mathrm{C}$ chemokine receptor type 4 (CXCR4), and multidrug resistance gene 1 promoters. ${ }^{65-68}$

\section{MicroRNA-regulated replication of OVs}

The recent discovery that some specific microRNAs (miRNAs) are specifically dysregulated in cancer cells provides a new avenue for targeted replication of OVs in cancer cells. miRNAs are a class of small noncoding RNA molecules that regulate gene expression posttranscriptionally by binding to complementary sequence on $\mathrm{mRNA}$ targets and then blocking protein translation via the RNA-induced silencing complex. miRNAs whose expression is lost or greatly reduced in cancer cells have been used to control the expression of critical viral genes of several OVs, thereby confining OV replication to those cancer cells. ${ }^{69,70}$ To date, however, miRNA-regulated OVs have not yet been studied in ovarian cancer.

\section{Ovarian cancer model systems}

Established ovarian cancer cell lines have been generated and characterized throughout the ovarian cancer literature. Much is known regarding the genetic perturbations within many of these lines, particularly with the recent publication of data from genome-wide sequencing strategies. ${ }^{71,72}$ There are also well-defined data with respect to the tumorigenic capacity when implanted into immune-compromised mice with respect to take rate, tumor latency, route of injection, and combined administration of standard chemotherapeutics for ovarian cancer (ie, platinum agents and taxanes). ${ }^{73-75}$ There are also concerted efforts by some groups to establish and use primary ovarian tumor cells directly from patients. For ovarian cancer, this not only entails growing cells from solid tumor biopsy specimens, but can be quite effectively performed by direct culturing of metastatic ovarian cancer cells from the malignant ascites fluid that accumulates in the majority of women with late-stage disease. ${ }^{76}$

The widely held belief is that epithelial ovarian cancer cells arise from lesions within the normal ovarian surface epithelial cells $;^{77,78}$ however, more recently it has emerged that alternative origins likely exist as well. Historically, ovarian cancer cells are compared with either primary cultures of normal ovarian surface epithelial cells from oophorectomy specimens or - what has been more widely done - immortalized counterparts of these cells are used. Ovarian surface epithelial (OSE) cells immortalized with simian virus 40 (SV40) T antigen originally generated by Auersperg's group have been commonly used, ${ }^{79,80}$ and since then human telomerase reverse transcriptase has also been applied. ${ }^{81}$ These immortal cell lines derived show no tumorigenic characteristics in culture and in mice, but retain normal epithelial cell properties. ${ }^{81,82}$ Additional molecular events, such as coexpression of E-cadherin, are required for SV40 T antigen-immortalized human OSE to acquire tumor-forming potential. ${ }^{83}$ To address the putative fallopian tube origin of high-grade serous ovarian cancer, efforts have been initiated to generate fallopian tube secretory epithelial cell lines. ${ }^{84}$

Mouse models typically entail human ovarian tumor cell line xenografts into immune-compromised mice. For example, ES2 cells and A2780 cell lines are quite aggressive and yield robust tumor and ascites growth within a short period. ${ }^{75,85}$ SKOV3ip1 cells are also useful for successful intraperitoneal (IP) injection and tumorigenesis studies ${ }^{86}$ For using mouse models that possess an intact immune system, there has been the development of transgenic mouse lines that yield bilateral ovarian tumors due to SV40 T antigen expression targeted to the mouse ovarian surface epithelium. ${ }^{87}$ This contrasts with human OSE cells immortalized with SV40 T antigen alone, which is nontumorigenic in mice. ${ }^{82}$ In addition, there is the utility of using the ID8 transformed mouse OSE cell line, which can establish tumors when injected into syngeneic $\mathrm{C} 57 \mathrm{Bl} / 6$ female mice. ${ }^{88}$

\section{OV candidates for ovarian cancer} Adenovirus

Members of the Adenoviridae family are DNA viruses that commonly cause mild and self-recovered upper respiratory 
tract and digestive tract infection in healthy people. There are 57 Ad serotypes identified in humans, ${ }^{89}$ of which Ad serotype 5 (Ad5) is most extensively studied and has been genetically modified into various recombinant conditionally replicative adenoviruses (CRAds) for treatment of cancer. CRAds possess specifically engineered elements in the viral genome that confer selective viral replication in cancer cells but disfavor replication in normal somatic cells. The best-known oncolytic CRAd is E1B 55-kDa gene-deleted Ad5 mutant d11520 (also known as Onyx-015, developed by Onyx Pharmaceuticals). ${ }^{90}$ E1B $55 \mathrm{kDa}$ protein has been shown in vitro to bind and inactivate the cellular tumor suppressor $\mathrm{p} 53$ protein, thereby blocking $\mathrm{p} 53$-induced apoptosis. Originally, it was believed that prevention of p53-mediated apoptosis by E1B $55 \mathrm{kDa}$ protein allowed wild-type (WT) Ads to replicate and propagate in normal cells, and hence Onyx-015 would only replicate in p53-defective cancer cells. However, E1B $55 \mathrm{kDa}$ protein was subsequently found also to be involved in late viral RNA nuclear export, and this mechanism, rather than p53 inhibition, is more likely to determine the tumor selectivity of Onyx-015. ${ }^{91}$ The effect of Onyx-015 treatment on ovarian cancer was tested in nude mice bearing xenografted human ovarian cancer cells. ${ }^{92}$ It was shown that Onyx-015 was able to enhance survival of animals bearing human ovarian OVCAR3 or A2780/CP70 tumors. This finding promoted Onyx-015 entrance into human clinical trials for ovarian cancer in early 2000.

Two other CRAds, containing a similar but not identical 24-bp deletion in the $\mathrm{Rb}$-binding conserved region 2 of the $E 1 A$ gene that abrogates the binding of E1A to $\mathrm{pRb}$, and designated d1922-947 and Ad5- $\Delta 24$, respectively, were developed to target tumor cells defective in the $\mathrm{Rb}$ pathway. ${ }^{64,93}$ Binding of E1A to $\mathrm{Rb}$ is required for Ad to drive S-phase entry and cell cycle progression for optimal viral replication. ${ }^{94}$ Aberrant $\mathrm{Rb}$ pathway and consequent abnormal G1-S checkpoint, which can complement E1A with mutated conserved region 2 and permit the replication of Ad5- $\Delta 24$ and d1922-947 in such tumor cells, are found in over $90 \%$ of human cancers, including ovarian cancer. ${ }^{95}$ In vitro studies have shown that compared with WT Ad5 and Onyx-015, d1922-947 induced greater cytotoxicity in IGROV1 and OVCAR4 ovarian cancer cells and certain other types of cancer cells. ${ }^{64,96}$ In the IGROV1 xenograft mouse model, d1922-947 displayed potent antiovarian tumor activity, comparable with WT Ad5. ${ }^{96}$ It has also been shown that d1922-947 improved antitumor activities in other cancer xenograft models, compared with Onyx-015 and WT Ad. ${ }^{64}$
In addition to the genetic manipulation of the $E 1 A$ and $E 1 B$ genes, other approaches have also been exploited to optimize the oncolytic activity of CRAds for ovarian cancer, including tropism modification, TSP-controlled viral replication, arming Ads with therapeutic genes, chemotherapy-Ad combination therapy, and novel viral delivery methods. ${ }^{97}$

\section{Tropism modification}

The Coxsackie adenovirus receptor (CAR) is the main cellular receptor for Ad5. However, CAR is expressed on most normal human epithelial tissues and is often expressed at lower levels on ovarian and other primary cancer cells. ${ }^{98,99}$ The large variation of CAR expression on tumor cells, at least in part, contributes to the oncolytic inconsistence often observed between preclinical and clinical studies using Onyx015 virus, eg, its relative ineffectiveness in the early clinical trials for ovarian cancer. To circumvent this CAR-dependent cell entry in order to better target tumor cells specifically, the Ad5 capsid was genetically modified to incorporate an RGD motif that binds to integrins $\alpha_{\mathrm{v}} \beta_{3}$ and $\alpha_{\mathrm{v}} \beta_{5}$, which are highly expressed on certain cancer cells, including most ovarian cancers. ${ }^{100-102}$ The derivative vector, Ad5- $\Delta 24$ RGD, replicated and killed several different human ovarian cancer cell lines (Hey, OV-4, and SKOV3) as efficiently as Ad5-WT E1A-RGD, and also replicated efficiently in ovarian cancer primary cell spheroids. ${ }^{59}$ Moreover, treatment of CB17 severe combined immunodeficiency (SCID) mice bearing xenografted OVCAR3 tumors showed potent antiovarian cancer therapeutic effects. Another strategy used to overcome the inherent CAR deficiency on most ovarian cancer cells was to replace the Ad5 CAR-binding motif with that from Ad3. This enabled the chimeric vector Ad5/3 to enter cells through a CAR-independent, Ad3 receptor-dependent pathway. The Ad3 receptor, recently identified as the desmoglein-2 protein, ${ }^{103}$ is expressed at high levels on most ovarian cancer cells. ${ }^{104}$ When compared with Ad5lucRGD, the replication-incompetent luciferase (luc)-expressing Ad5/3 (Ad5/3luc) was more efficient in transduction of cultured ovarian cancer cell lines SKOV3. ip1, Hey, and OV-4 as well as in human primary ovarian cancer cells isolated directly from patients. ${ }^{61}$ Both Ad5/3luc and Ad5lucRGD were superior to WT Ad5luc in infectivity in vitro and in a CD1 nude mice model with subcutaneous (SC) Hey tumor xenografts following intratumoral injection of viruses. Other in vitro studies also confirmed that Ad5/3 modification achieved higher infectivities in ovarian cancer cells than the mutant RGD variant. ${ }^{68,105}$ In another study, ovarian cancer retargeting was achieved by coating 
Ads with receptor-binding antibody-conjugated polymer that was covalently linked to Ad capsid. ${ }^{62}$

\section{TSP-controlled Ad viral replication}

With CRAds, the tumor specificity was improved using TSPs to drive E1A expression, which allowed limited viral replication in normal cells but not in tumor cells, and reduced the host toxicity caused by CRAds. Several TSPs (as mentioned previously) have been tested in ovarian cancer cell lines and in human primary ovarian cancer cells isolated from patients. TSPs in combination with tropism modification (Ad5/3 or RGD) have shown to have greater oncolytic activity and significantly reduced liver toxicity in an in vitro and in vivo ovarian cancer xenograft model, compared with WT Ad5 or no-TSP control viruses. ${ }^{68,105-107}$

\section{Armed CRAds}

Candidate genes that have been engineered into CRAds potentially to augment oncolytic virotherapy include cellsuicide genes, genes that modify tumor microenvironment for enhanced viral infectivity, and immunoregulatory genes. Onyx-015 armed with the HSV TK gene has been shown to suppress tumor growth in the presence or absence of the prodrug ganciclovir in the MDAH 2774 xenograft tumor model. ${ }^{108}$ Interestingly, ganciclovir appeared to inhibit Onyx015 and reduced its tumor suppression effects. Similar results were also seen using Ad5/3- $\Delta 24-\mathrm{TK}$ virus. ${ }^{109} \mathrm{~A}$ CRAd was engineered to carry the $C X C R-4$ promoter and the tissue inhibitor of metalloproteinase 2 (TIMP2) gene that targets cellular metalloproteinases to inhibit tumor growth and dissemination. The resultant mutant virus, Ad5/3-CXCR4TIMP2, showed more efficient in vitro killing of ovarian cancer cells than the unarmed viruses ${ }^{67}$ However, the in vivo antitumor activity of Ad5/3-CXCR4-TIMP2 remains to be investigated.

\section{Chemotherapy-CRAd combination therapy}

Accumulating evidence indicates that chemotherapeutic agents or radiotherapy can be combined with OVs such as the CRAds to significantly enhance therapeutic effects in the treatment of cancers compared with either treatment alone. For example, the combination of Ad5/3- $\Delta 24$ with gemcitabine (a nucleoside analog), or epirubicin (a DNAintercalating anthracycline drug) resulted in greater therapeutic efficacy than either agent alone in ovarian cancer xenograft models. ${ }^{110}$ Combination of d1922-947 with paclitaxel or combination of the survivin promoter-containing vector CRAd.S-RGD with cisplatin also had significantly greater therapeutic benefits than single-agent treatments in ovarian cancer xenograft models. ${ }^{111,112}$ It was suggested that cisplatin and gemcitabine might act to increase viral replication, whereas paclitaxel and d1922-947 together induced aberrant mitotic slippage and multinucleation, leading to a more efficient apoptotic cell death.

\section{Enhancement of viral delivery}

Ads commonly cause subclinical human infections that usually induce protective neutralizing antibody responses in virus-infected people. For example, approximately 40\%-69\% of the adult population in the US are seropositive to Ad5. ${ }^{113}$ Preexisting anti-Ad5 antibodies in humans may reduce clinical efficacy of intratumorally injected Ad5-based vectors and represents a serious hindrance to the clinical application of systemically administered CRAds. Furthermore, direct injection of Ads may also cause higher systemic toxicity responses in patients, especially in the liver. In order to overcome these barriers, two strategies have been developed to enhance the therapeutic effects of Ad delivery on ovarian cancer. The first strategy is to coat the viral particles with liposome polymers, which would shield the antibody-binding sites on Ad capsids from preexisting neutralizing antibodies and also reduce antiviral humoral responses as well as liver uptake of the virus. ${ }^{114,115}$ Using this method, liposome-coated Ad5 armed with the antiangiogenic agent endostatin had increased in vitro transfection capacity in SKOV3 cell lines and also had enhanced antitumor effects in a SC SKOV3 xenograft nude mouse model when the virus was administered through intravenous (IV) administration. ${ }^{116}$ Another strategy for targeted delivery enhancement is to load mesenchymal stem cells (MSCs) with Ads before viral administration. One advantage of MSCs over other potential virus-carrier cells is that MSCs can be readily generated from patients' own adipose tissues and grown to a large quantity. MSCs have been shown to display preferable homing to ovarian tumors after IP injection in an ovarian cancer xenograft model. ${ }^{117}$ It has also been demonstrated that Ad5/3 and Ad-RGD viruses could efficiently infect MSCs without induction of severe cytopathic effects. ${ }^{117}$ When tested for antiovarian cancer effects, MSCs loaded with Ad5/3 or Ad5-D24-RGD induced cell killing of ovarian cancer cells and significantly suppressed tumor growth and prolonged survival in the SKOV3 xenograft animal model. ${ }^{117,118}$ MSCs loaded with Ad5-D24-RGD were as effective a strategy as administration of the virus alone, but showed a dramatic decrease in systemic spread of the virus, suggesting much less virus-associated systemic toxicity in the treated mice. ${ }^{118}$ 


\section{Herpes simplex viruses}

Herpes simplex viruses 1 and 2 (HSV-1 and HSV-2) are members of Herpesviridae, a virus family of large, enveloped, dsDNA viruses. Both viruses infect most humans, with about two-thirds of the adult population being seropositive for one or both of the viruses.

HSV-1 and HSV-2 have been developed as oncolytic agents by genetically modifying the viral genomes for more targeted replication in cancer cells. For example, in the HSV-1 vector Baco-1, both copies of the viral $\gamma 34.5$ genes encoding the ICP34.5 neurovirulence factor were deleted and a green fluorescent protein (GFP)-expression cassette was inserted elsewhere in the viral genome. ${ }^{119}$ ICP34.5 recruits cellular protein phosphatase- $1 \alpha$ to dephosphorylate eIF $2 \alpha$, thereby counteracting the PKR signaling pathway. ${ }^{120}$ ICP34.5 also interferes with the phosphatidylinositol 3-kinase (PI3K) pathway. ${ }^{121} \mathrm{HSV}-1716$, an attenuated HSV-1 mutant with deletion of a 759-bp DNA fragment and showing ICP34.5 deficient phenotype, ${ }^{122}$ was among the first OVs to treat ovarian cancer in animal models. ${ }^{123} \mathrm{HSV}-1716$ treatment significantly suppressed tumor burden in SCID mice bearing human ovarian SKOV3 or A2780 tumors. Moreover, treatments with PA-1 teratocarcinoma cells carrying HSV1716 showed greater antitumor activity compared with virus treatment alone. However, HSV-1716 and other similar HSV-1 vectors with deletion in $\gamma 34.5$ genes, although showing tumor cell-killing abilities in preclinical studies, did not significantly affect tumor growth or improve prognosis in early clinical trials. ${ }^{124,125}$ To improve the potency of this first generation of the HSV-1 vector Baco-1, a hyperfusogenic glycoprotein gene of the gibbon ape leukemia virus (GALV.fus) was inserted by replacing the GFP-expression cassette. ${ }^{126}$ When the resultant engineered HSV-1, called Synco-2D, was compared with Baco-1 for its induced cytopathic effects on human ovarian cancer cells Hey-8 and SKOV3 in vitro, Synco-2D produced more pronounced syncytial formation and killed infected ovarian cancer cells more rapidly. In nude mice bearing IP Hey- 8 xenografts, IP injection of Synco-2D resulted in $100 \%$ of mice surviving to the end of the experiment and $75 \%$ of the treated mice being tumor-free, whereas only $60 \%$ of Baco-1-treated mice survived and all bore large tumors. All mice died in the control mock-treated cohort. Another engineered HSV-2 based GALV.fus-expressing oncolytic vector was tested in ovarian cancer. This vector, named FusOn-H2, contains an additional modification, ie, deletion of the viral ICP10 gene. ICP10 encodes in its $\mathrm{N}$-terminus a serine/threonine protein kinase domain that can activate the Ras signaling pathway and is required for efficient HSV-2 replication in normal cells. ${ }^{127}$ It was also shown that FusOn-H2 had a greater ability to eradicate tumors in nude mice bearing IP disseminated SKOV3 xenografts (more than $80 \%$ ) than Baco-1 (12\%). These data suggest that oncolytic HSV armed with GALV.fus may provide a novel therapy for ovarian cancer.

In another recent study, it has been shown that carrier cell-based delivery of oncolytic HSV-1 mutants can improve antitumor effects against ovarian cancer through the amplification of the viral load and avoidance of neutralizing antibodies. This was tested using attenuated HSV-1 mutant, Hh101, and using human peritoneal mesothelial cells as cell carriers in a nude mice model xenografted with SKOV3 tumor cells. ${ }^{128}$ In this model, Hh101 carried in mesothelial cells significantly improved the antitumor activities of the virus compared with the Hh101 virus-alone treatment. Hh101 is an HSV-1 mutant isolated from Vero cells coinfected with HF10, a naturally attenuated virus derived from the HSV-1 HF strain, ${ }^{129}$ and hrR3, an early generation of HSV-1 vector deleted in $U_{L} 39$ gene encoding ribonucleotide reductase. ${ }^{130}$ Hh101 has also been shown to effectively treat disseminated peritoneal colon carcinoma in a BALB/c mouse model. ${ }^{131}$

The role of host immune responses in HSV-mediated oncolytic virotherapy has been studied. Using HSV-1716 and a syngeneic mouse model of murine ID8 ovarian cancer cells expressing VEGF, it was demonstrated that IP injection of HSV-1716 led to the suppression of tumor growth and enhancement of mouse survival. ${ }^{132}$ Virus treatment-induced infiltration of monocytes and dendritic cells to the tumor and also upregulated the level of IFN-inducible chemokines, including monokine-induced gamma IFN protein (called MIG, now known as CXCL9) and IFN gamma-induced protein 10 (IP-10). ${ }^{132}$ Activated natural killer (NK) cells or $\mathrm{CD}^{+}$ $\mathrm{T}$ cells were also recruited to the tumor microenvironment, likely mediated by MIG and IP-10. In addition, tumor cells infected with HSV-1716 expressed viral glycoproteins on the cell surface and were highly phagocytosed by dendritic cells, leading to induction of vaccination effects. These data indicated that HSV-1716, and possibly other oncolytic HSV vectors as well, exert their most oncolytic activities when they elicit both antitumor immune responses as well as direct killing of tumor cells.

\section{Vaccinia virus}

$\mathrm{VV}$ is a large enveloped dsDNA virus belonging to the Poxviridae family. Some strains of VV used as attenuated live-virus vaccines against smallpox have been studied as replicating OV agents. These VV vaccines can be further 
attenuated to increase cancer selectivity by deletion of specific viral genes. Some of these genes include the viral $T K$ and VV growth factor (VGF) genes. ${ }^{133,134} \mathrm{TK}$ is critical for VV DNA synthesis, particularly to infect normal cells, where nucleotide pools are typically low. Deletion of the $V G F$ gene renders the virus defective in its ability to stimulate cell proliferation of noncycling cells to prime them for VV infection.

The deleted $T K$ gene is often replaced with ectopic reporter genes (eg, luc, Escherichia coli beta galactosidase gene lacZ, or GFP) or therapeutic genes (eg, granulocytemacrophage colony-stimulating factor $[G M-C S F]$ ) to facilitate monitoring virus spread or to improve antitumor activities, respectively. For example, rVV4 is a hyper-attenuated recombinant derivative of the vaccine strain Lister of VV, containing both $l a c Z$ and $l u c$ inserted into the $T K$ gene. ${ }^{135}$ rVV4 has shown oncolytic efficacy in both human ES-2 ovarian cancer cells in nude mice (significant tumor reduction with no ascites accumulation and $100 \%$ of mice survived to 70 days posttreatment; controls survived to 28 days) and Defb29 Vegf mouse ovarian tumor cells in C57B1/6 mice (infection led to significant tumor necrosis and cell death, and survival up to 63 days after treatment; controls survived to 42 days). Another $T K$-deletion VV construct, JX-594, was engineered from the Wyeth vaccine strain of VV. JX-594 also has insertions of lacZ or $l u c$, and expresses human GM-CSF. This virus can infect and kill human ovarian cancer cells in vitro and specifically infect autochthonous ovarian tumors when injected IP into transgenic FVB/N mice expressing SV40 T antigen driven by the Müllerian inhibitory substance type II receptor promoter. ${ }^{87,136}$ In addition to singly $T K$ deleted VV, the $T K$ and $V G F$ double-deleted virus (vvDD) has also been tested in ovarian cancer. vvDD has potent oncolytic activities in mouse MOSEC cells, human ovarian cancer cell line A2780, and human primary ovarian tumor cells in vitro, and in nude mice bearing IP A2780 tumors. ${ }^{137}$ When vvDD was armed with a yeast cytosine deaminase $(C D)$ gene that can been paired with prodrug 5 -fluorouracil for enhanced chemotherapy, the resultant vvDD-CD virus in combination with 5-fluorouracil displayed higher antitumor activity than vvDD-CD alone in the syngeneic IP MOSEC C57B1/6 mouse model. ${ }^{137}$

VV combined with other therapeutic agents can also augment its oncolytic activities. Recombinant VV as an oncolytic monotherapy requires repeated treatments; however, induced neutralizing antibodies can potentially limit the booster effect of subsequent inoculations, particularly in those who have been previously vaccinated against smallpox. To circumvent this, cotreatment with COX2 inhibitors reduces the generation of neutralizing antibodies due to VV administration. ${ }^{138}$ Mouse ovarian tumor MOSEC cells expressing luciferase injected into $\mathrm{C} 57 \mathrm{Bl} / 6$ mice and treated with $\mathrm{COX} 2$ inhibitor exhibited higher viral titers when rechallenged with rVV4 with significantly fewer antibodies than control mice untreated with COX2 inhibitor. The doubly treated mice also showed reduced tumor growth and longer survival compared with rVV4 or COX2 treatments alone. Alternatively, limitation of repeated administration can be circumvented by using different OVs. It has been shown that VV injection followed by injection of another OV, the alphavirus Semliki Forest, or vice versa, induced longer survival than either virus alone in $\mathrm{C} 57 \mathrm{Bl} / 6$ mice with MOSEC IP engraftments. ${ }^{139}$ Moreover, sequential treatment of MOSEC tumor-bearing C57Bl/6 mice with VV expressing ovalbumin and Semliki Forest virus expressing ovalbumin induced higher $\mathrm{CD} 8^{+}$ T-cell immune responses and longer animal survival than treatment with single virus alone. These results suggest that the efficacy of oncolytic virotherapy could be improved by employing different OVs and combining tumor antigenspecific immunotherapy.

\section{Myxoma virus}

MYXV is a poxvirus with a very restrictive rabbit-specific tropism in nature but which is completely apathogenic and safe to all non-lagomorphs tested, including mice, rats, and humans. In vitro, MYXV has been shown to infect and kill a wide variety of human cancer cells. ${ }^{140}$ The tumor selectivity of MYXV depends in part on dysregulated intracellular signaling pathways in the cancer cells, specifically the PI3K pathway and the activation of Akt (p-AKT). ${ }^{141,142}$ An ankyrin repeat-containing host-range protein of MYXV termed M-T5 can directly bind to and induce the kinase activity of Akt, which allows more robust viral replication in cancer cells. ${ }^{135}$ Recently, MYXV has been shown to possess potent oncolytic activity against human epithelial ovarian cancers from both cell lines and ascites-derived primary patient cells. OVCAR3, OVCA429, SKOV3 human ovarian cancer cell lines, and $\sim 55 \%$ of patient samples tested demonstrated susceptibility to MYXV killing in monolayer. ${ }^{143}$ In an in vitro model of ovarian cancer metastasis, cells cultured in ultralow attachment plates to form multicellular spheroids (the hypothesized vehicles for ovarian cancer metastasis) were also infected by MYXV. Spheroids formed from both cell lines and ascites-derived patient samples that were infected with MYXV were killed and showed decreased reattachment upon reintroduction to adherent culture, 
thus demonstrating the potential antimetastatic properties of this virus. The oncolytic properties of MYXV correlated with the level of p-Akt found in specific cell culture conditions, ie, an increase in p-Akt levels in monolayer showed greater killing, whereas decreased p-Akt levels in spheroids had little killing until reattachment in adherent culture. Thus it is predicted that MYXV will have particular utility for targeting metastatic spread of this cancer, but this remains to be tested in vivo.

\section{Measles virus}

MV is a member of the Paramyxoviridae family and is an enveloped, single-stranded, negative-sense RNA virus that causes rash, fever, runny nose, cough, muscle pain, and red eyes in an infected person. A live attenuated MV vaccine strain called Edmonston has been developed as an effective oncolytic virus for treatment of ovarian cancer in preclinical studies. ${ }^{144}$ Upon viral infection, the hemagglutinin envelope glycoprotein of the oncolytic MV binds to the cellular receptor CD46, a cofactor for inactivation of complement, and subsequently the fusion glycoprotein induces fusion of viral-cell membranes. ${ }^{56}$ Expression of hemagglutinin and fusion proteins on the surface of virus-infected cells results in intercellular fusion of multiple neighboring uninfected cells with the infected cell, a characteristic MV-induced cytopathic effect (CPE) called syncytia. Extensive formation of syncytia causes apoptotic cell death of not only infected cells but also uninfected neighboring cells, a bystander killing that may augment the oncolytic activity of MV. CPE effects, however, are only induced when infection takes place in cells with more than a required minimum density of CD46 receptor expression. ${ }^{145}$ Normal cells usually express only a low level of CD46. Therefore, infection of normal cells does not cause CPE and cell death. The safety of oncolytic MV has been demonstrated in measles replication-permissive animal models, including a CD46 transgenic mouse model and macaque models. ${ }^{146,147}$ The CD46 receptor is highly expressed in ovarian cancer cells, rending ovarian cancer an ideal target for MV virotherapy. ${ }^{148-150}$ A modified oncolytic MV expressing the soluble extracellular domain of human carcinoembryonic antigen (CEA) was created to monitor viral replication noninvasively in vivo. ${ }^{151} \mathrm{MV}-\mathrm{CEA}$ was able to kill a panel of ovarian cancer cells in vitro. Furthermore, intratumoral injection of MV-CEA led to $80 \%$ complete tumor regression in SC SKOV3.ip1-engrafted athymic nude mice, and IP administration of the virus greatly enhanced the survival of IP SKOV3.ip1 xenograft mice. ${ }^{144}$ In addition, it was also confirmed that CEA expression could be used as a marker for the presence of MV-CEA replication post-viral administration. These results provided the basis for the subsequent phase I clinical trial with MV-CEA in patients with recurrent ovarian cancer. Interestingly, in a following study testing multiple dosages in an IP xenograft animal model, Peng et al reported that IP treatments with either six doses of $10^{3}$ or single or six doses of $10^{4}, 10^{5}$, or $10^{7}$ median tissue culture infective dose $\left(\mathrm{TCID}_{50}\right) \mathrm{MV}-\mathrm{CEA}$ resulted in equivalent anti-tumor effects. ${ }^{152}$ These results suggested that in vivo tumor growth and MV infection/replication could reach an equilibrium state regardless of the initial infection doses. In addition to CEA, the thyroidal sodium iodide symporter (NIS) was also inserted into the MV genome for monitoring viral propagation, which can be mapped by serial radioiodine imaging. Results using MV-NIS suggested that MV-CEA and MV-NIS had comparable tumor suppression activity in vivo. ${ }^{153} \mathrm{~A}$ more attenuated Edmonston strain-derived MV vaccine, called MV-Moraton, and another live virus vaccine from the Paramyxoviridae family, Jeryl Lynn mumps, have also been investigated for their possible oncolytic activity. The results showed that both viruses have potent antiovarian tumor activities comparable with MV-CEA in xenograft models. ${ }^{154}$ MV-Moraton and Jeryl Lynn mumps are commercially available vaccines and have been used in more than 300 million people. The proven safety profile in humans and the capacity for mass production make these two viruses appealing OV candidates for cancer therapy in general.

A tropism-modified MV has also been generated and studied for its potential application in ovarian cancer. To minimize potential CD46-associated immune suppression and virus sequestration by non-target tissues after MV administration, the hemagglutinin protein of MV was genetically modified to incorporate a single-chain antibody ( $\mathrm{scFv}$ ) specific for FR $\alpha$ while eliminating its CD46 binding. ${ }^{60} \mathrm{FR} \alpha$ has been found to be overexpressed in various cancers including $90 \%$ of ovarian cancer, whereas in normal tissue, FR $\alpha$ is only expressed at the apical surface of polarized epithelial cells. ${ }^{155,156}$ The recombinant virus MV-FR $\alpha$ reduced its background viral infection levels on normal cells and targeted only FR $\alpha$-expressing cancer cells. The virus retained complete antiovarian cancer activity of the parental $\mathrm{MV}$, as demonstrated in SC and IP SKOV3.ip1 xenograft models.

MSCs have also been tested as the virus-carrying vehicle in an attempt to protect MV from preexisting neutralizing antibody and to improve targeted delivery of the virus to ovarian tumors. It was shown that MV-infected MSCs could efficiently reach and infiltrate into IP SKOV3.ip1 tumors for virus delivery in measles-naive athymic mice and also 
in mice passively immunized with human measles immune serum. ${ }^{157}$ This resulted in effective enhancement of animal survival in the tumor-bearing cohorts. In contrast, no such effect was displayed when passively immunized mice were treated with naked virus or uninfected MSCs.

\section{Reovirus}

Reoviruses are nonenveloped viruses with a genome consisting of 10-12 dsRNA segments. Reoviruses were initially named respiratory enteric orphan viruses because they were commonly isolated from human respiratory and gastrointestinal tracts but are not apparently associated with human diseases. Reovirus serotype 3 Dearing strain has been developed as an OV under the trade name Reolysin (Oncolytics Biotech). ${ }^{158}$ It is very difficult to genetically modify reovirus using classic reverse-genetic approaches because of the segmented dsRNA viral genome. Nevertheless, the WT, unaltered Reolysin, has potent intrinsic oncolysis activities. Reovirus specifically targets and kills cancer cells with an activated Ras signaling pathway that leads to the inhibition of PKR activation. ${ }^{55}$ In normal cells, it is believed that PKR is activated by reovirus genomic dsRNA segments and viral dsRNA transcripts. As a result, reovirus cannot express sufficient viral proteins for continued replication in normal cells, in contrast to the productive virus infection in tumor cells that possess deficient PKR activation. It has also been suggested that the oncolytic activity of reovirus is mediated by TNF-related apoptosis-inducing ligand (TRAIL)-induced, caspase 3/8-dependent apoptosis. ${ }^{159,160}$

Mutations in the Ras signaling pathway are often found in patients with ovarian cancer, ${ }^{161}$ indicating that ovarian cancer is a potential therapeutic target for reovirus. In an early in vitro study, Reolysin efficiently infected and killed four human ovarian cancer cell lines (MDAH2774, PA-1, SKOV3, and SW626), primary ovarian cancer cells from patient samples, but not a normal ovarian fibroblast cell line (NOV-31). ${ }^{162}$ It was further demonstrated that intratumoral injection of Reolysin induced regression of SC SKOV3 tumors in nude mice, and IP administration of the virus inhibited ascites formation and prolonged survival of treated mice in an IP MDAH2774 xenograft model. This study also showed that Reolysin specifically and effectively infected distal colon tumors in the SC flank, but not normal tissue surrounding the tumor, following IV delivery of the virus. Reolysin infection of ovarian cancer cells could also sensitize the cells to recombinant TRAIL, an anticancer agent currently being tested in clinical trials, ${ }^{163}$ possibly via downregulation of cellular FLICE/caspase-8 inhibitory protein. ${ }^{159}$
This suggests that combination of reovirus and TRAIL could be more effective than either regimen alone in the treatment of ovarian cancer.

\section{Vesicular stomatitis virus}

VSV is an enveloped, negative-stranded RNA virus of the Rhabdoviridae family. Viruses in this family are attractive OV candidates, because with the exception of rabies, they are rarely associated with diseases in humans. Moreover, few people have preexisting immunity in most populations worldwide.

VSV binds to and enters mammalian cells through an unidentified receptor that is ubiquitously expressed in normal cells and malignant cells. ${ }^{164}$ Infection of normal cells strongly induces interferon-mediated antiviral responses, and thus virus replication is blocked. By contrast, cancer cells frequently have defective interferon signaling pathways, allowing for unchecked viral replication. A dysregulated PKR pathway is the one of the key factors for determination of the tumor selectivity of VSV. ${ }^{165}$ Viral protein expression and replication likely kill virus-infected cancer cells by the induction of apoptotic cell death during metaphase, which is triggered by inhibition of mitotic progression by VSV infection. ${ }^{166}$

It has been shown that VSV is a potent oncolytic in a wide variety of cancer models, ${ }^{167}$ including ovarian cancer. ${ }^{168-170}$ In vitro, a VSV vector-expressing GFP (VSV-GFP) was able to efficiently infect and kill various ovarian cancer cell lines and ovarian surface epithelial cells transformed with SV40 T antigen within 3 days. ${ }^{169}$ By contrast, infection of normal primary human ovarian epithelial cells was detected in only about $5 \%$ of the cells, and no cytotoxicity effects were observed 3 weeks postinfection. The antiovarian cancer efficacy of VSV-GFP has also been tested using an immunocompetent white spotting variant (Wv) mouse model. ${ }^{169}$ Wv mice have a naturally occurring point mutation in the c-kit gene, causing defects in the development of germ cells. ${ }^{171,172}$ Nearly $100 \%$ of homozygous Wv mice develop ovarian epithelial tumors, defined as tubular adenomas, as early as 3 months of age. ${ }^{173}$ This type of epithelial ovarian tumor is benign, but can gain increasing neoplastic changes in older mice. Treatment of tumor-bearing Wv mice with VSV-GFP via intrabursal, IP, or IV administration was shown to greatly reduce the tumor burden without inducing detectable toxicity effects. ${ }^{169}$ Examination of GFP signals in treated Wv mice 10 days after virus injection indicated that VSV selectively targeted the in situ ovarian tumor, while no GFP expression was detected in any other organs and tissues. In another study, 
using an IP human ES-2 ovarian cancer xenograft model, Stojdl and colleagues showed that a VSV virus (AV2) with mutated matrix protein and enhanced ability to induce IFN responses in normal cells enhanced survival of virus-treated animals. ${ }^{170}$ AV2 has slightly decreased oncolytic activity in ovarian cancer cells in vitro compared with WT VSV. However, AV2 is highly attenuated in BALB/C mice, suggesting that it may be safer for clinical applications.

\section{Maraba mirus}

Like VSV, MRB is a member of the Rhabdoviridae family. In a comparison of oncolytic activity across this family, MRB was shown to have the highest degree of killing in an array of cancer cell lines, including those from ovarian sources. ${ }^{174}$ To improve replication and decrease toxicity, two point mutations were made in MRB (MRB MG1) that were homologous to two point mutations made in VSV that improved replication of VSV. In an ES-2 xenograft model of ovarian cancer, low doses of MRB MG1 showed significant decreases in tumor burden. Moreover, there was a dosedependent tumor response to MRB MG1, and it demonstrated better efficacy at all doses when compared directly with a VSV construct.

\section{Sindbis virus}

SINV is a member of the Togaviridae family that is an enveloped, positive-stranded RNA virus that infects natural host birds and transfers vector mosquitoes. Infection in humans can occur when a person is bitten by infected mosquitoes, but generally causes very mild symptoms. SINV as a blood-borne pathogen is stable in the bloodstream, which may enable more efficient systemic delivery of the virus. SINV has an inherent tropism for tumor cells. The SINV receptor LAMR is overexpressed in ovarian cancer cells ${ }^{175}$ and many other types of tumor cells, ${ }^{176}$ and is important to mediate cancer cell migration and metastasis. ${ }^{177}$ Like VSV, SINV is highly sensitive to IFN, and thus can only replicate in cancer cells with acquired genetic defects in the IFN-signaling pathway, but not in normal cells with intact innate immune responses. ${ }^{178}$ Productive infection, at least with VSV, likely causes cancer cell death by inducing apoptosis. ${ }^{179}$

SINV virotherapy of ovarian cancer was first tested using an SCID mouse model bearing IP human ES-2 ovarian cancer xenografts and a syngeneic C57Bl/6 mouse model with IP engraftment of murine MOSEC ovarian cancer cells. ${ }^{180}$ It was found that IP injection of SINV significantly suppressed tumor growth in both models. Survival analysis in the syngeneic model also confirmed the antitumor activities of SINV. An attenuated laboratory SINV strain, AR339, also suppresses tumor growth in a human OMC-3 ovarian cancer xenograft model. ${ }^{181}$ By using in vivo imaging of SINV expressing firefly luciferase and ES-2 cells expressing Renilla luciferase, combined with histologic analysis, virus infection colocalized with the tumor tissue in vivo, suggesting that virus infection is tumor-specific. In addition to the oncolysis of cancer cells, SINV also was also shown to induce a potent bystander antitumor immunity. ${ }^{178}$ This antitumor immunity is likely mediated by activation of NK cells. ${ }^{182}$ Correspondingly, SINV oncolytic vectors expressing interleukin (IL)-12 or IL-15, two cytokines known to elicit antitumor activity by activation of natural killer cells, exhibit more potent antitumor activity than SINV expressing lacZ. ${ }^{180,182}$

\section{Echovirus type I}

EV1 is a nonenveloped, single-stranded, icosahedral RNA virus of the Picornaviridae family. EV1 is isolated from the gastrointestinal tract and causes no or mild upper respiratory infection. The EV1 receptor integrin $\alpha_{2} \beta_{1}$ is highly expressed on ovarian cancer cells, but is only present on normal surface epithelium at a low level. ${ }^{183}$ In vitro, EV1 induces strong cytopathic effects in various ovarian cancer cell lines, but not in immortalized human OSE cells or human peripheral blood mononuclear cells. ${ }^{184}$ EV1 can also infect and kill multicellular spheroids of ovarian cancer cells DOV13. When tested in SCID mice bearing OVHS-1 xenografts, both intratumoral and IP injections of EV1 were shown to suppress tumor burden significantly. In an SC xenograft model, none of EV1-treated mice reached experiment end points (tumors exceeding $20 \%$ of body weight) after the experiment was ended 14 weeks post-virus administration, whereas all mice without virus treatment reached end points within 3 weeks. These results suggest EV1 is also a potential oncolytic virus candidate for the treatment of ovarian cancer.

\section{Clinical applications}

Clinical studies using OVs to treat ovarian cancer is still in its infancy. As of April 2012, results from three phase I clinical trials in ovarian cancer have been published, involving Onyx015, ${ }^{185}$ Ad5- $\Delta 24-R G D,{ }^{186}$ and measles virus MV-CEA. ${ }^{149}$ A phase I clinical trial testing JX-594 in patients with different types of cancers including ovarian cancer has also been published. ${ }^{187}$ Ad5-D24-GMCSF and Ad5/3-D24-GMCSF have also been evaluated under compassionate use regulated by the Finnish Medicines Agency FIMEA. ${ }^{188,189}$ In addition, there are two ongoing trials with Reolysin in ovarian cancer 
and one ongoing trial with attenuated VV GL-ONC1 for all peritoneal metastatic cancers including ovarian cancer, according to the NIH website ClinicalTrials.gov. Although early phase trials mainly address the safety, maximum tolerated dose, and toxicity spectrum of OVs, antitumor efficacy, viral replication, and antibody responses are also analyzed. Clinical efficacies are assessed by Response Evaluation Criteria in Solid Tumor (RECIST) criteria and cancer antigen (CA)-125 response. CA-125, also known as mucin 16, is a protein biomarker for recurrence of ovarian cancer. ${ }^{190}$ In all studies, eligible ovarian cancer patients have persistent or recurrent ovarian cancer, fallopian tube cancer, or primary peritoneal cancer after prior treatment with chemotherapy. The enrollees are older than 18 years and have adequate organ function. Participating patients, except for those in the JX-594 trial, receive administration of OVs through an IP catheter. All these clinical studies have shown that OVs were well tolerated, and no maximum tolerated doses were reached in any of the trials. Encouraging antitumor responses were observed in all but the Onyx-015 trial. Summaries of the clinical studies are provided in Table 2.

\section{Onyx-0I5}

The first human OV trial for ovarian cancer was conducted with adenovirus Onyx-015 in 16 patients. ${ }^{185}$ Four dose levels of virus $\left(1 \times 10^{9}, 1 \times 10^{10}, 3 \times 10^{10}\right.$, and $1 \times 10^{11}$ plaqueforming units $[\mathrm{pfu}]$ ) were tested in this trial. For a particular dose level, Onyx-015 was administered to patients daily for 5 days (one cycle) every 4 weeks. These patients received a total of 35 cycle treatments, with a mean of two cycles per patient. Most patients experienced common toxicity criteria grade 1 or 2 flu-like syndrome and abdomen pain after virus infusion. Only one patient who received $1 \times 10^{10}$ pfu exhibited common toxicity criteria grade 3 abdominal pain and grade 3 diarrhea, and the patient's toxicity profile was considered dose-limiting. No grade 4 toxicity was noted in any patient. This toxicity study indicates that Onyx-015 administration is safe at the highest dosage tested. Viral DNA was detected 10 days after the last dose of virus in five of eight patients who were subjected to polymerase chain reaction (PCR) testing of peritoneal specimens. No viral DNA was detected in the blood samples in these patients. Interestingly, viral DNA was still detected in one patient 354 days after final virus treatment. These data, however, were not sufficient to prove the presence of viral replication since an increase in viral genome copy number was not shown. Antiadenovirus antibody responses were evident in 12 of 13 patients that were examined. Unfortunately, there was no clear evidence of antitumor activities induced by Onyx-15 in this trial. Four of the 16 patients showed brief stable disease after more than two cycles of Onyx-015, but soon developed progressive disease. Eventually, all patients stopped virotherapy because of development of progressive disease, except one who was removed from the trial due to Onyx-015 doselimiting toxicity.

\section{Ad5- $\Delta 24-R G D$}

The tropism-modified Ad5- $\Delta 24-\mathrm{RGD}$ virus has been engineered to improve cancer-targeting and the oncolytic activity of early adenovirus vectors, such as Onyx-015, in preclinical studies. Consistently, a phase I clinical trial with Ad5- $\Delta 24-$ RGD has yielded promising antiovarian cancer responses. ${ }^{186}$ In this clinical trial, vector dosages of Ad5- $\Delta 24-R G D$ ranging from $1 \times 10^{9}$ viral particles per day $(\mathrm{vp} / \mathrm{d})$ to $1 \times 10^{12} \mathrm{vp} / \mathrm{d}$, with increase of $1 / 2 \log \mathrm{vp} / \mathrm{d}$ in each successive cohort tested in 21 patients, of whom 18 patients

Table 2 Summaries of clinical trials of oncolytic virotherapy in patients with ovarian cancer

\begin{tabular}{|c|c|c|c|c|c|c|c|}
\hline \multirow[t]{2}{*}{ Virus type } & \multirow[t]{2}{*}{ Name } & \multirow{2}{*}{$\begin{array}{l}\text { Study } \\
\text { phase }\end{array}$} & \multirow{2}{*}{$\begin{array}{l}\text { Number } \\
\text { of patients }\end{array}$} & \multicolumn{2}{|l|}{ Efficacy } & \multirow[t]{2}{*}{ Toxicity } & \multirow[t]{2}{*}{ Refs } \\
\hline & & & & Best responses & CA-I 25 & & \\
\hline MV & MV-CEA & 1 & 21 & I4 SD & $5 P R$ & Mild & 149 \\
\hline \multirow[t]{4}{*}{ Ads } & Onyx-15 & I & 16 & No clear response & No response & I DLT, I5 mild & 185 \\
\hline & Ad5- $\Delta 24-R G D$ & I & 21 & I5 SD & $7 \mathrm{MR}$ & Mild & 186 \\
\hline & Ad5- $\triangle 24-G M C S F$ & $\mathrm{CU}^{* *}$ & $4^{*}(20)$ & I CR, I SD, I MR & I CR, I PR, I SD & Mild & 188 \\
\hline & Ad5/3- $\Delta 24-G M C S F$ & $\mathrm{CU} * *$ & $4^{*}(2 I)$ & I SD & I MR & Mild & 189 \\
\hline \multirow[t]{2}{*}{ VV } & JX-594 & I & $2 *(23)$ & $2 S D$ & & Mild & 187 \\
\hline & GL-ONCI & $\mathrm{I} / \mathrm{II}$ & Recruiting & & & & 193 \\
\hline \multirow[t]{2}{*}{ Reovirus } & Reolysin & 1 & Recruiting & & & & 194 \\
\hline & Reolysin (with paclitaxel) & II & Recruiting & & & & 195 \\
\hline
\end{tabular}

Notes: *Number of patients with ovarian cancer, out of the total number of patients with various types of cancer, indicated in the parentheses, in the corresponding clinical trial; **studies under compassionate use regulated by the Finnish Medicines Agency FIMEA. With regard to CA-I 25 tumor markers, MR, PR, SD, and CR indicate a less than $29 \%$ decrease, a more than $30 \%$ decrease, stabilization, and a normal level in tumor marker, respectively.

Abbreviations: CR, complete response; PR, partial response; MR, minor response; SD, stable disease; PD, progressive disease; CU, compassionate use. 
had recurrent ovarian cancer. Virus was delivered daily for 3 consecutive days, and the patients were followed up on days $0-3,7,14$, and 28 to evaluate toxicity, virus replication, and antitumor efficacy. As for the clinical study with Onyx-015, Ad5- $\Delta 24-R G D$ treatment did not cause significant toxicity. Although no partial or complete responses were observed, 15 patients (71\%) were shown to have stable disease. In addition, seven patients (33\%) had deceased CA-125 levels, and four of them had $>20 \%$ reduction. RGD-specific viral DNA was detected in ascites in 16 of 21 patients by quantitative real-time (qRT) PCR after virus treatment. More importantly, increased viral DNA copy number was detected at various time points after day 3 of virus treatment in seven patients, suggesting viral replication in the cancer cells. Immunohistochemistry analysis of ascites from selected patients confirmed the infection of ovarian cancer cells by the virus. Dose-dependent antiadenovirus neutralizing antibody response was generally detected in ascites and serum in all patients. Unlike Onyx-015, Ad5- $\Delta 24-$ RGD DNA was also found in serum (ten patients), saliva (ten patients), and urine (nine patients), probably due to high replication activity of Ad5- $\Delta 24-R G D$ in the IP cavity, leading to the dissemination of the virus.

\section{MV-CEA}

MV-CEA has been tested in 21 patients with recurrent ovarian cancer in a phase I trial study. ${ }^{149}$ Patients were treated with seven escalating doses of MV-CEA $\left(10^{3}-10^{9}\right.$ TCID $_{50}$ at $1-\log$ increments) every 4 weeks for up to six cycles. No dose-limiting toxicity was observed with MV-CEA. Most toxicities were grade 1 or 2 fever, fatigue, and abdominal pain. Fourteen of the 21 patients $(67 \%)$ had stable disease with median duration of 92.5 days. Nine of the 14 patients with stable disease $(64 \%)$ were in the three highest dose levels, indicating dose-dependent outcomes. CA-125 levels were demonstrated to decrease $>30 \%$ in five patients. Median overall survival of the patients in this trial was 12.15 months, while in similar patient populations the median survival is expected to be 6 months. Viral DNA was detected in the blood in four patients by qRT-PCR, but no virus shedding was detected in saliva and urine in any patient. CEA levels were elevated in the peritoneal fluid in one patient in the $10^{8}-$ TCID $_{50}$ cohort and two in the $10^{9}-$ TCID $_{50}$ cohort, and in the serum in all three patients in the $10^{9}-$ TCID $_{50}$ cohort. No antibody responses to MV-CEA were observed. This might have resulted from preexisting high baseline anti-measles antibody in enrolled patients who were required to be immunized with measles for safety consideration in this first-ever human virotherapy trial with MV. Since MV predominantly utilizes the CD46 receptor for cell entry, the authors also examined the expression of CD46 in tumor specimens in 15 patients whose tissues were available, attempting to investigate the effect of CD46 expression on the oncolytic activities of MV-CEA. Thirteen of the 15 patients showed high-level expression of CD46; however, no association of CD46 expression with clinical efficacy was observed. Due to the small patient sample size and different dosages used in this initial clinical trial, whether CD46 expression is associated with clinical efficacy remains to be identified.

\section{Ad5-D24-GMCSF and Ad5/3-D24- GMCSF}

Two phase I clinical trials have been conducted to test whether GM-CSF could facilitate induction of antitumor immunity in the context of oncolytic Ad vectors Ad5- $\Delta 24$ and $A d 5 / 3-\Delta 24 .{ }^{188,189}$ Twenty patients with 15 different types of cancers (four patients with ovarian cancer) and 21 patients with twelve different types of cancers (four patients with ovarian cancer) were treated with Ad5-D24-GMCSF and Ad5/3-D24-GMCSF, separately. Viruses were administered using ultrasound-guided intratumoral injection or intracavity injection as in ovarian cancer patients, with one-fifth of the dose given IV. The starting dose of virus was $8 \times 10^{9} \mathrm{vp} / \mathrm{d}$ in the Ad5-D24-GMCSF trial, $8 \times 10^{10} \mathrm{vp} / \mathrm{d}$ in the Ad5/3-D24GMCSF trial, and escalated to $4 \times 10^{11} \mathrm{vp} / \mathrm{d}$ in both trials. Both studies showed that virus treatments were well tolerated and induced antitumoral and antiviral immune responses, as measured by the activation of tumor- and virus-specific cytotoxic $\mathrm{T}$ lymphocytes. Clinical benefits were also observed in some patients, including four patients with ovarian cancer in the Ad5-D24-GMCSF trial and one of four patients in the Ad5/3-D24-GMCSF trial.

\section{JX-594}

Taking the lead that VV has adapted to acquire stability in the bloodstream and is capable of rapid spread to distal tissues, ${ }^{191}$ a phase I clinical trial was designed to test whether JX-594 could target metastatic tumors via IV infusion. Escalating dosages $\left(1 \times 10^{5}-3 \times 10^{7} \mathrm{pfu} / \mathrm{kg}\right)$ were administered in 23 patients with nine different types of cancers, including two patients with recurrent ovarian cancer. ${ }^{187}$ Results from this study showed that JX-594 could selectively infect tumors after IV infusion in a dose-dependent manner. Viral infection of tumors was detected in all eight patients receiving the two highest doses of JX-594, but in only two out of 15 patients receiving lower doses. Antitumor activities were 
also observed and appeared to be dose-dependent. One of the two patients with ovarian cancers receiving a lower dose of JX-594 was virus-negative in tumor but showed stable disease for more than 4 weeks after treatment. The other patient receiving the second- highest dose was virus-positive in the tumor and had stable disease for more than 16 weeks. The most common virus-associated adverse side effect was grade $1 / 2$ flu-like symptoms, indicating that it is safe to administer JX-594 via this IV route.

\section{GL-ONCI}

GL-ONC1 (also named GLV-1h68) is an attenuated Lister strain VV with insertion of Renilla luciferase-GFP fusion gene, lac $Z$ and $\beta$-glucuronidase reporter genes in the F14.5L, J2R (TK), and A56R (hemagglutinin) loci of the viral genome. ${ }^{192}$ This OV is being tested in a phase I/II trial in patients with advanced peritoneal cancers, which include ovarian cancer patients. ${ }^{193}$

\section{Reolysin}

The two ongoing Reolysin clinical trials are (1) a phase I trial in patients that did not respond to platinum chemotherapy, and (2) a phase II trial to investigate the safety and efficacy of Reolysin in combination with paclitaxel compared with a paclitaxel regime alone. ${ }^{194,195}$ In the first clinical trial, patients were treated with Reolysin via both IV and IP routes. Among the patients that have been treated, viral replication could be detected in peritoneal and ovarian cancer cells following IV administration. ${ }^{196}$ This is the first to reveal that reovirus can reach peritoneal and ovarian cancer via systemic delivery.

\section{Conclusions}

The use of live viruses specifically to kill cancer cells dates back as early as the beginning of the last century. ${ }^{197}$ However, the field of oncolytic virotherapy did not truly expand as a systematic inquiry until two decades ago, when genetic approaches were first applied to modify OVs in order specifically to target cancer cells. ${ }^{63,90}$ In 2005, Ad vector H101 was approved in China as the world's first approved OV for treatment of head and neck cancer in combination with chemotherapy. ${ }^{198}$ Currently two oncolytic viruses, Reolysin and OncoVEX, a herpex simplex type 1 virus-based oncolytic therapeutic agent, have entered pivotal phase III trials. JX-594 is also being tested in phase II clinical trials for liver cancer and metastatic colorectal cancer, and has shown great promise in preliminary results. Early last year, OncoVEX was acquired by Amgen in a deal that has been valued at up to US\$1 billion. Although promising, we are still far from fulfilling the great potential of oncolytic virotherapy. One key challenge is our as-of-yet modest understanding of the multifactorial interactions between the tumor, its microenvironment, OVs, and the host immune responses to both the $\mathrm{OV}$ and the cancer cells.

Although preclinical and clinical studies have confirmed the safety and potential of OV therapy for ovarian cancer, many key outstanding questions remain to be addressed.

1. How can targeted delivery of OVs to ovarian tumor tissue be improved? Preexisting antiviral antibodies and OV-induced immune responses to the virus can hinder the delivery of OVs to ovarian tumor sites. The carrier cell-based delivery strategy may overcome this hurdle, for example when tumor-homing MSCs are used to ferry virus to tumor tissues. The feasibility of this "Trojan horse" approach to virus delivery in the clinical setting remains to be tested.

2. What are the operative mechanisms for OV-mediated antiovarian cancer effects? The parameters that determine the susceptibility of individual ovarian cancer patients to virotherapy is still not clear in clinical settings. In addition, few studies have addressed the complex interactions between OVs and the various transformed and noncancerous cells that inhabit all tumor microenvironments. Most importantly, the effects of residual or dysfunctional antitumor immunity and the immune-evasion strategies by ovarian carcinoma cells on the oncolytic efficacy have not been clearly elucidated. Numerous lines of evidence have indicated that host immunity acts as a "double-edged sword" in oncolytic virotherapy. On one hand, the rapid generation of host immune responses to the virus could preempt the time window for effective viral replication within the tumor bed. On the other hand, virus-tumor interactions can also liberate immune responses against tumor antigens and induce long-lasting bystander antitumor immunity. A major unanswered question remains: does the direct killing of cancer cells by OVs or the virus-induced antitumor immunity play the major role in OV-induced cancer regression?

3. Can OVs target the more drug-resistant OCICs? The ability to target chemotherapy-resistant OCICs might determine the outcome of any new treatment for advanced ovarian cancer, particularly in combination with standard chemotherapies. So far, OVs have not been tested for their capability to infect and kill OCICs.

4. How can the oncolytic potency of OVs be improved? First, OVs in combination with chemotherapy have shown synergistic effects in treating ovarian cancer in 
cell culture and animal models. Traditionally, OVs always enter clinical trials not as the first-line treatment but as a final-stage salvage attempt. Instituting earlier combination regimens of OVs with conventional therapeutics may be a far better strategy than testing OV monotherapy after standard treatments have already failed. Also, sequential employment of genetically different OVs for virotherapy has been shown be more effective to induce antitumor immunity in preclinical studies. ${ }^{139}$ This approach leverages the observation that different OVs have very distinct tumor selectivities, which may facilitate targeting the cell heterogeneity associated with many cancers, including ovarian cancer.

5. Finally, preclinical studies have also indicated that many OVs can be armed with efficacy-improving therapeutic genes. These adjunct genes can express immunoregulatory factors such as IL-12 and GM-CSF that can stimulate antitumor immunity by activating NK and $\mathrm{CD}^{+} \mathrm{T}$ cells. JX-594 and OncoVEX, being tested in clinical trials, are both armed with $G M-C S F$. It is worth noting that most current approaches aim to boost antitumor immune responses in cancer virotherapy by activating effector immune cells such as NK and CD8 ${ }^{+}$ $\mathrm{T}$ cells. However, immunotherapy for cancer, particularly ovarian cancer, has increasingly focused on inhibiting regulatory $\mathrm{T}$ cells (Tregs) that block the development of effective T-cell immune responses to tumor antigens. ${ }^{199}$ Circulating or tissue-resident Tregs may block effective antitumor immune responses in late-stage ovarian cancer, creating an effective immunosuppressive environment in the tumor. New strategies to combine OVs with Tregtargeted suppression could be a key to achieve complete regression of patients with ovarian cancer. OVs are an ideal vehicle to deliver locally therapeutic gene products that could assist in mounting more effective cellular antitumor responses. Alternatively, OVs can be combined with drugs that inhibit Tregs, such as cyclophosphamide. In addition to its direct cytotoxic effect on cancer cells, gemcitabine has also been shown to eliminate Tregs selectively, and preclinical models indicate that gemcitabine can synergize well with many OVs.

In many ways, the current state of oncolytic virotherapy is similar to the situation with the cytotoxic chemotherapy drugs first developed over half a century ago, with one notable exception. Like the older cytotoxic drugs still being used routinely in the clinic today, many OVs also exhibit potent anticancer properties in the preclinical setting, but there is a limit to what can be learned in animal models, and their correct exploitation in cancer patients now requires appropriate clinical trials to teach oncologists how to exploit them effectively. In stark contrast to the classic chemotherapeutics that now comprise the standard of care for so many cancers, the single most notable characteristic of OV therapies tested to date is their extraordinary safety record. This should encourage the oncology field to be optimistic that exploiting the great potential of oncolytic virotherapy now needs to be conducted in the clinical arena. Despite the challenges ahead, advances in our understanding of tumorigenesis, antitumor immunity, and molecular biology and anticancer properties of OVs have helped and will continue to shape the translation of preclinical and clinical studies into significant clinical outcomes for cancer patients.

\section{Acknowledgments}

Grant McFadden's laboratory is funded by NIH R01 grants AI080607 and CA13854, R21 grant CA149869, and the Bankhead Coley Cancer Research Foundation grant 1BT02. Trevor Shepherd's laboratory is funded by CCSRI grant 20109 and with funds from the London Run for Ovarian Cancer.

\section{Disclosure}

The authors report no conflicts of interest in this work.

\section{References}

1. Jemal A, Siegel R, Ward E, et al. Cancer statistics, 2008. CA Cancer J Clin. 2008;58(2):71-96.

2. Cannistra SA. Cancer of the ovary. N Engl J Med. 2004;351(24): 2519-2529.

3. Chambers AF, Groom AC, MacDonald IC. Dissemination and growth of cancer cells in metastatic sites. Nat Rev Cancer. 2002;2(8):563-572.

4. Lengyel E. Ovarian cancer development and metastasis. Am J Pathol. 2010;177(3):1053-1064.

5. Naora H, Montell DJ. Ovarian cancer metastasis: integrating insights from disparate model organisms. Nat Rev Cancer. 2005;5(5):355-366.

6. Bast RC Jr, Hennessy B, Mills GB. The biology of ovarian cancer: new opportunities for translation. Nat Rev Cancer. 2009;9(6):415-428.

7. Bowtell DD. The genesis and evolution of high-grade serous ovarian cancer. Nat Rev Cancer. 2010;10(11):803-808.

8. Cancer Genome Atlas Research Network. Integrated genomic analyses of ovarian carcinoma. Nature. 2011;474(7353):609-615.

9. Marquez RT, Baggerly KA, Patterson AP, et al. Patterns of gene expression in different histotypes of epithelial ovarian cancer correlate with those in normal fallopian tube, endometrium, and colon. Clin Cancer Res. 2005;11(17):6116-6126.

10. Crum CP, Drapkin R, Miron A, et al. The distal fallopian tube: a new model for pelvic serous carcinogenesis. Curr Opin Obstet Gynecol. 2007;19(1):3-9.

11. Pearce CL, Templeman C, Rossing MA, et al. Association between endometriosis and risk of histological subtypes of ovarian cancer: a pooled analysis of case-control studies. Lancet Oncol. 2012;13(4):385-394.

12. Romero I, Bast RC Jr. Minireview: human ovarian cancer: biology, current management, and paths to personalizing therapy. Endocrinology. 2012;153(4):1593-1602. 
13. Reya T, Morrison SJ, Clarke MF, Weissman IL. Stem cells, cancer, and cancer stem cells. Nature. 2001;414(6859):105-111.

14. Lobo NA, Shimono Y, Qian D, Clarke MF. The biology of cancer stem cells. Annu Rev Cell Dev Biol. 2007;23:675-699.

15. Al-Hajj M, Wicha MS, Benito-Hernandez A, Morrison SJ, Clarke MF. Prospective identification of tumorigenic breast cancer cells. Proc Natl Acad Sci U S A. 2003;100(7):3983-3988.

16. Collins AT, Berry PA, Hyde C, Stower MJ, Maitland NJ. Prospective identification of tumorigenic prostate cancer stem cells. Cancer Res 2005;65(23):10946-10951.

17. O'Brien CA, Pollett A, Gallinger S, Dick JE. A human colon cancer cell capable of initiating tumour growth in immunodeficient mice. Nature. 2007;445(7123):106-110.

18. Ricci-Vitiani L, Lombardi DG, Pilozzi E, et al. Identification and expansion of human colon-cancer-initiating cells. Nature. 2007;445(7123):111-115.

19. Ma SF, Nishikawa M, Katsumi H, Yamashita F, Hashida M. Liver targeting of catalase by cationization for prevention of acute liver failure in mice. J Control Release. 2006;110(2):273-282.

20. Li C, Heidt DG, Dalerba P, et al. Identification of pancreatic cancer stem cells. Cancer Res. 2007;67(3):1030-1037.

21. Singh SK, Hawkins C, Clarke ID, et al. Identification of human brain tumour initiating cells. Nature. 2004;432(7015):396-401.

22. Quintana E, Shackleton M, Sabel MS, Fullen DR, Johnson TM, Morrison SJ. Efficient tumour formation by single human melanoma cells. Nature. 2008;456(7222):593-598.

23. Bapat SA, Mali AM, Koppikar CB, Kurrey NK. Stem and progenitorlike cells contribute to the aggressive behavior of human epithelial ovarian cancer. Cancer Res. 2005;65(8):3025-3029.

24. Szotek PP, Pieretti-Vanmarcke R, Masiakos PT, et al. Ovarian cancer side population defines cells with stem cell-like characteristics and Mullerian inhibiting substance responsiveness. Proc Natl Acad Sci US A. 2006;103(30):11154-11159.

25. Zhang S, Balch $\mathrm{C}$, Chan MW, et al. Identification and characterization of ovarian cancer-initiating cells from primary human tumors. Cancer Res. 2008;68(11):4311-4320.

26. Alvero AB, Chen $\mathrm{R}, \mathrm{Fu} \mathrm{HH}$, et al. Molecular phenotyping of human ovarian cancer stem cells unravels the mechanisms for repair and chemoresistance. Cell Cycle. 2009;8(1):158-166.

27. Ma L, Lai D, Liu T, Cheng W, Guo L. Cancer stem-like cells can be isolated with drug selection in human ovarian cancer cell line SKOV3. Acta Biochim Biophys Sin (Shanghai). 2010;42(9):593-602.

28. Baba T, Convery PA, Matsumura N, et al. Epigenetic regulation of $\mathrm{CD} 133$ and tumorigenicity of $\mathrm{CD} 133^{+}$ovarian cancer cells. Oncogene. 2009;28(2):209-218.

29. Stewart JM, Shaw PA, Gedye C, Bernardini MQ, Neel BG, Ailles LE Phenotypic heterogeneity and instability of human ovarian tumorinitiating cells. Proc Natl Acad Sci U S A. 2011;108(16):6468-6473.

30. Gao MQ, Choi YP, Kang S, Youn JH, Cho NH. CD $24^{+}$cells from hierarchically organized ovarian cancer are enriched in cancer stem cells. Oncogene. 2010;29(18):2672-2680.

31. Kryczek I, Liu S, Roh M, et al. Expression of aldehyde dehydrogenase and CD133 defines ovarian cancer stem cells. Int J Cancer. 2011;130(1):29-39.

32. Silva IA, Bai S, McLean K, et al. Aldehyde dehydrogenase in combination with CD133 defines angiogenic ovarian cancer stem cells that portend poor patient survival. Cancer Res. 2011;71(11):3991-4001.

33. Wang YC, Yo YT, Lee HY, et al. ALDH1-bright epithelial ovarian cancer cells are associated with CD44 expression, drug resistance, and poor clinical outcome. Am J Pathol. 2012;180(3):1159-1169.

34. Meirelles K, Benedict LA, Dombkowski D, et al. Human ovarian cancer stem/progenitor cells are stimulated by doxorubicin but inhibited by Mullerian inhibiting substance. Proc Natl Acad Sci U S A. 2012;109(7):2358-2363.

35. Cavallo F, De Giovanni C, Nanni P, Forni G, Lollini PL. 2011: the immune hallmarks of cancer. Cancer Immunol Immunother. 2011;60(3):319-326.
36. Hanahan D, Weinberg RA. Hallmarks of cancer: the next generation. Cell. 2011;144(5):646-674.

37. Sato E, Olson $\mathrm{SH}, \mathrm{Ahn} \mathrm{J}$, et al. Intraepithelial $\mathrm{CD}^{+}$tumor-infiltrating lymphocytes and a high $\mathrm{CD}^{+} /$regulatory $\mathrm{T}$ cell ratio are associated with favorable prognosis in ovarian cancer. Proc Natl Acad Sci U SA. 2005;102(51):18538-18543.

38. Stumpf M, Hasenburg A, Riener MO, et al. Intraepithelial CD8-positive T lymphocytes predict survival for patients with serous stage III ovarian carcinomas: relevance of clonal selection of T lymphocytes. $\mathrm{Br} J$ Cancer. 2009;101(9):1513-1521.

39. Freeman SM, McCune C, Robinson W, et al. The treatment of ovarian cancer with a gene modified cancer vaccine: a phase I study. Hum Gene Ther. 1995;6(7):927-939.

40. Gong J, Nikrui N, Chen D, et al. Fusions of human ovarian carcinoma cells with autologous or allogeneic dendritic cells induce antitumor immunity. J Immunol. 2000;165(3):1705-1711.

41. Weng D, Song B, Durfee J, et al. Induction of cytotoxic T lymphocytes against ovarian cancer-initiating cells. Int $J$ Cancer. 2011;129(8):1990-2001.

42. Loercher AE, Nash MA, Kavanagh JJ, Platsoucas CD, Freedman RS. Identification of an IL-10-producing HLA-DR-negative monocyte subset in the malignant ascites of patients with ovarian carcinoma that inhibits cytokine protein expression and proliferation of autologous T cells. J Immunol. 1999;163(11):6251-6260.

43. Massagué J. TGF beta in cancer. Cell. 2008;134(2):215-230.

44. Dunfield LD, Dwyer EJ, Nachtigal MW. TGF beta-induced Smad signaling remains intact in primary human ovarian cancer cells. Endocrinology. 2002;143(4):1174-1181.

45. Hirte H, Clark DA. Generation of lymphokine-activated killer cells in human ovarian carcinoma ascitic fluid: identification of transforming growth factor-beta as a suppressive factor. Cancer Immunol Immunother. 1991;32(5):296-302.

46. Fung-Kee-Fung M, Oliver T, Elit L, Oza A, Hirte HW, Bryson P. Optimal chemotherapy treatment for women with recurrent ovarian cancer. Curr Oncol. 2007;14(5):195-208.

47. Vaha-Koskela MJ, Heikkila JE, Hinkkanen AE. Oncolytic viruses in cancer therapy. Cancer Lett. 2007;254(2):178-216.

48. Hartkopf AD, Fehm T, Wallwiener D, Lauer U. Oncolytic virotherapy of gynecologic malignancies. Gynecol Oncol. 2011;120(2):302-310.

49. Hartkopf AD, Fehm T, Wallwiener M, Lauer U. Oncolytic viruses to treat ovarian cancer patients - a review of results from clinical trials. Geburtshilfe Frauenheilkd. 2012;72:132-136.

50. Yoneyama M, Fujita T. Recognition of viral nucleic acids in innate immunity. Rev Med Virol. 2010;20(1):4-22.

51. Sen GC, Sarkar SN. The interferon-stimulated genes: targets of direct signaling by interferons, double-stranded RNA, and viruses. Curr Top Microbiol Immunol. 2007;316:233-250.

52. Critchley-Thorne RJ, Simons DL, Yan N, et al. Impaired interferon signaling is a common immune defect in human cancer. Proc Natl Acad Sci U S A. 2009;106(22):9010-9015.

53. Rabinovich GA, Gabrilovich D, Sotomayor EM. Immunosuppressive strategies that are mediated by tumor cells. Annu Rev Immunol. 2007;25:267-296.

54. Downward J. Targeting RAS signalling pathways in cancer therapy. Nat Rev Cancer. 2003;3(1):11-22.

55. Strong JE, Coffey MC, Tang D, Sabinin P, Lee PW. The molecular basis of viral oncolysis: usurpation of the Ras signaling pathway by reovirus. EMBO J. 1998;17(12):3351-3362.

56. Dorig RE, Marcil A, Chopra A, Richardson CD. The human CD46 molecule is a receptor for measles virus (Edmonston strain). Cell. 1993;75(2):295-305

57. Wang KS, Kuhn RJ, Strauss EG, Ou S, Strauss JH. High-affinity laminin receptor is a receptor for Sindbis virus in mammalian cells. $J$ Virol. 1992;66(8):4992-5001.

58. Bergelson JM, Shepley MP, Chan BM, Hemler ME, Finberg RW. Identification of the integrin VLA-2 as a receptor for echovirus 1. Science. 1992;255(5052):1718-1720. 
59. Bauerschmitz GJ, Lam JT, Kanerva A, et al. Treatment of ovarian cancer with a tropism modified oncolytic adenovirus. Cancer Res. 2002;62(5):1266-1270.

60. Hasegawa K, Nakamura T, Harvey M, et al. The use of a tropismmodified measles virus in folate receptor-targeted virotherapy of ovarian cancer. Clin Cancer Res. 2006;12(20 Pt 1):6170-6178.

61. Kanerva A, Wang M, Bauerschmitz GJ, et al. Gene transfer to ovarian cancer versus normal tissues with fiber-modified adenoviruses. Mol Ther. 2002;5(6):695-704.

62. Morrison J, Briggs SS, Green NK, et al. Cetuximab retargeting of adenovirus via the epidermal growth factor receptor for treatment of intraperitoneal ovarian cancer. Hum Gene Ther. 2009;20(3):239-251.

63. Martuza RL, Malick A, Markert JM, Ruffner KL, Coen DM. Experimental therapy of human glioma by means of a genetically engineered virus mutant. Science. 1991;252(5007):854-856.

64. Heise C, Hermiston T, Johnson L, et al. An adenovirus E1A mutant that demonstrates potent and selective systemic anti-tumoral efficacy. Nat Med. 2000;6(10):1134-1139.

65. Lam JT, Kanerva A, Bauerschmitz GJ, et al. Inter-patient variation in efficacy of five oncolytic adenovirus candidates for ovarian cancer therapy. J Gene Med. 2004;6(12):1333-1342.

66. Tsuruta Y, Pereboeva L, Breidenbach M, et al. A fiber-modified mesothelin promoter-based conditionally replicating adenovirus for treatment of ovarian cancer. Clin Cancer Res. 2008;14(11):3582-3588.

67. Yang SW, Cody JJ, Rivera AA, et al. Conditionally replicating adenovirus expressing TIMP2 for ovarian cancer therapy. Clin Cancer Res. 2011;17(3):538-549.

68. Zhu ZB, Lu B, Park M, et al. Development of an optimized conditionally replicative adenoviral agent for ovarian cancer. Int J Oncol. 2008;32(6):1179-1188.

69. Hikichi M, Kidokoro M, Haraguchi T, et al. MicroRNA regulation of glycoprotein B5R in oncolytic vaccinia virus reduces viral pathogenicity without impairing its antitumor efficacy. Mol Ther. 2011;19(6):1107-1115.

70. Kelly EJ, Hadac EM, Greiner S, Russell SJ. Engineering microRNA responsiveness to decrease virus pathogenicity. Nat Med. 2008;14(11):1278-1283.

71. Hanrahan AJ, Schultz N, Westfal ML, et al. Genomic complexity and AKT dependence in serous ovarian cancer. Cancer Discov. 2012;2(1):56-67.

72. Marcotte R, Smith HW, Sanguin-Gendreau V, McDonough RV, Muller WJ. Mammary epithelial-specific disruption of c-Src impairs cell cycle progression and tumorigenesis. Proc Natl Acad Sci U S A. 2012;109(8):2808-2813.

73. D'Incalci M, Colombo T, Ubezio P, et al. The combination of yondelis and cisplatin is synergistic against human tumor xenografts. Eur $J$ Cancer. 2003;39(13):1920-1926.

74. Sharma A, Straubinger RM, Ojima I, Bernacki RJ. Antitumor efficacy of taxane liposomes on a human ovarian tumor xenograft in nude athymic mice. J Pharm Sci. 1995;84(12):1400-1404.

75. Shaw TJ, Senterman MK, Dawson K, Crane CA, Vanderhyden BC. Characterization of intraperitoneal, orthotopic, and metastatic xenograft models of human ovarian cancer. Mol Ther. 2004;10(6):1032-1042.

76. Shepherd TG, Theriault BL, Campbell EJ, Nachtigal MW. Primary culture of ovarian surface epithelial cells and ascites-derived ovarian cancer cells from patients. Nat Protoc. 2006;1(6):2643-2649.

77. Auersperg N, Wong AS, Choi KC, Kang SK, Leung PC. Ovarian surface epithelium: biology, endocrinology, and pathology. Endocr Rev. 2001;22(2):255-288.

78. Bell DA, Scully RE. Early de novo ovarian carcinoma. A study of fourteen cases. Cancer. 1994;73(7):1859-1864.

79. Auersperg N, Maines-Bandiera SL, Dyck HG, Kruk PA. Characterization of cultured human ovarian surface epithelial cells: phenotypic plasticity and premalignant changes. Lab Invest. 1994;71(4):510-518.

80. Wong AS, Kim SO, Leung PC, Auersperg N, Pelech SL. Profiling of protein kinases in the neoplastic transformation of human ovarian surface epithelium. Gynecol Oncol. 2001;82(2):305-311.
81. Li NF, Broad S, Lu YJ, et al. Human ovarian surface epithelial cells immortalized with hTERT maintain functional $\mathrm{pRb}$ and $\mathrm{p} 53$ expression. Cell Prolif. 2007;40(5):780-794.

82. Ong A, Maines-Bandiera SL, Roskelley CD, Auersperg N. An ovarian adenocarcinoma line derived from SV40/E-cadherintransfected normal human ovarian surface epithelium. Int J Cancer. 2000;85(3):430-437.

83. Auersperg N, Pan J, Grove BD, et al. E-cadherin induces mesenchymalto-epithelial transition in human ovarian surface epithelium. Proc Natl Acad Sci US A. 1999;96(11):6249-6254.

84. Levanon K, Ng V, Piao HY, et al. Primary ex vivo cultures of human fallopian tube epithelium as a model for serous ovarian carcinogenesis. Oncogene. 2010;29(8):1103-1113.

85. Anand N, Murthy S, Amann G, et al. Protein elongation factor EEF1A2 is a putative oncogene in ovarian cancer. Nat Genet. 2002;31(3):301-305.

86. Li C, Price JE, Milas L, et al. Antitumor activity of poly(L-glutamic acid)-paclitaxel on syngeneic and xenografted tumors. Clin Cancer Res. 1999;5(4):891-897.

87. Connolly DC, Bao R, Nikitin AY, et al. Female mice chimeric for expression of the simian virus $40 \mathrm{TAg}$ under control of the MISIIR promoter develop epithelial ovarian cancer. Cancer Res. 2003;63(6):1389-1397.

88. Roby KF, Taylor CC, Sweetwood JP, et al. Development of a syngeneic mouse model for events related to ovarian cancer. Carcinogenesis. 2000;21(4):585-591.

89. Lynch JP 3rd, Fishbein M, Echavarria M. Adenovirus. Semin Respir Crit Care Med. 2011;32(4):494-511.

90. Bischoff JR, Kirn DH, Williams A, et al. An adenovirus mutant that replicates selectively in p53-deficient human tumor cells. Science. 1996;274(5286):373-376.

91. O'Shea CC, Johnson L, Bagus B, et al. Late viral RNA export, rather than p53 inactivation, determines ONYX-015 tumor selectivity. Cancer Cell. 2004;6(6):611-623.

92. Heise C, Ganly I, Kim YT, Sampson-Johannes A, Brown R, Kirn D. Efficacy of a replication-selective adenovirus against ovarian carcinomatosis is dependent on tumor burden, viral replication and p53 status. Gene Ther. 2000;7(22):1925-1929.

93. Fueyo J, Gomez-Manzano C, Alemany R, et al. A mutant oncolytic adenovirus targeting the $\mathrm{Rb}$ pathway produces anti-glioma effect in vivo. Oncogene. 2000;19(1):2-12.

94. Felsani A, Mileo AM, Paggi MG. Retinoblastoma family proteins as key targets of the small DNA virus oncoproteins. Oncogene. 2006;25(38):5277-5285.

95. Sherr CJ, McCormick F. The RB and p53 pathways in cancer. Cancer Cell. 2002;2(2):103-112.

96. Lockley M, Fernandez M, Wang Y, et al. Activity of the adenoviral E1A deletion mutant d1922-947 in ovarian cancer: comparison with E1A wild-type viruses, bioluminescence monitoring, and intraperitoneal delivery in icodextrin. Cancer Res. 2006;66(2):989-998.

97. Toth K, Wold WS. Increasing the efficacy of oncolytic adenovirus vectors. Viruses. 2010;2(9):1844-1866.

98. Tomko RP, Xu R, Philipson L. HCAR and MCAR: the human and mouse cellular receptors for subgroup $\mathrm{C}$ adenoviruses and group B coxsackieviruses. Proc Natl Acad Sci U S A. 1997;94(7): 3352-3356.

99. Douglas JT, Kim M, Sumerel LA, Carey DE, Curiel DT. Efficient oncolysis by a replicating adenovirus (ad) in vivo is critically dependent on tumor expression of primary ad receptors. Cancer Res. 2001;61(3):813-817.

100. Cannistra SA, Ottensmeier C, Niloff J, Orta B, DiCarlo J. Expression and function of beta 1 and alpha v beta 3 integrins in ovarian cancer. Gynecol Oncol. 1995;58(2):216-225.

101. Kelly FJ, Miller CR, Buchsbaum DJ, et al. Selectivity of TAG72-targeted adenovirus gene transfer to primary ovarian carcinoma cells versus autologous mesothelial cells in vitro. Clin Cancer Res. 2000;6(11):4323-4333. 
102. Liapis H, Adler LM, Wick MR, Rader JS. Expression of alpha(v) beta3 integrin is less frequent in ovarian epithelial tumors of low malignant potential in contrast to ovarian carcinomas. Hum Pathol. 1997;28(4):443-449.

103. Wang $\mathrm{H}, \mathrm{Li} \mathrm{ZY}$, Liu Y, et al. Desmoglein 2 is a receptor for adenovirus serotypes 3, 7, 11 and 14. Nat Med. 2011;17(1):96-104.

104. Kanerva A, Mikheeva GV, Krasnykh V, et al. Targeting adenovirus to the serotype 3 receptor increases gene transfer efficiency to ovarian cancer cells. Clin Cancer Res. 2002;8(1):275-280

105. Rocconi RP, Zhu ZB, Stoff-Khalili M, et al. Treatment of ovarian cancer with a novel dual targeted conditionally replicative adenovirus (CRAd). Gynecol Oncol. 2007;105(1):113-121.

106. Barker SD, Coolidge CJ, Kanerva A, et al. The secretory leukoprotease inhibitor (SLPI) promoter for ovarian cancer gene therapy. J Gene Med. 2003;5(4):300-310.

107. Rein DT, Volkmer A, Beyer IM, et al. Treatment of chemotherapy resistant ovarian cancer with a MDR1 targeted oncolytic adenovirus. Gynecol Oncol. 2011;123(1):138-146.

108. Wildner O, Morris JC. The role of the E1B $55 \mathrm{kDa}$ gene product in oncolytic adenoviral vectors expressing herpes simplex virus-tk: assessment of antitumor efficacy and toxicity. Cancer Res. 2000;60(15):4167-4174.

109. Raki M, Hakkarainen T, Bauerschmitz GJ, et al. Utility of TK/ GCV in the context of highly effective oncolysis mediated by a serotype 3 receptor targeted oncolytic adenovirus. Gene Ther. 2007;14(19):1380-1388.

110. Raki M, Sarkioja M, Desmond RA, et al. Oncolytic adenovirus Ad5/3delta24 and chemotherapy for treatment of orthotopic ovarian cancer. Gynecol Oncol. 2008;108(1):166-172.

111. Ingemarsdotter CK, Baird SK, Connell CM, Oberg D, Hallden G, McNeish IA. Low-dose paclitaxel synergizes with oncolytic adenoviruses via mitotic slippage and apoptosis in ovarian cancer. Oncogene. 2010;29(45):6051-6063.

112. Zhang B, Liu Y, Zhang P, Wei Y, Yin X, Zheng J. A novel CRAd in combination with cisplatin enhanced the antitumor efficacy in ovarian cancer. Int J Gynecol Cancer. 2011;21(9):1540-1546.

113. Nwanegbo E, Vardas E, Gao W, et al. Prevalence of neutralizing antibodies to adenoviral serotypes 5 and 35 in the adult populations of The Gambia, South Africa, and the United States. Clin Diagn Lab Immunol. 2004;11(2):351-357.

114. Fisher KD, Stallwood Y, Green NK, Ulbrich K, Mautner V, Seymour LW. Polymer-coated adenovirus permits efficient retargeting and evades neutralising antibodies. Gene Ther. 2001;8(5):341-348.

115. Natsume A, Mizuno M, Ryuke Y, Yoshida J. Cationic liposome conjugation to recombinant adenoviral vector reduces viral antigenicity. Jpn J Cancer Res. 2000;91(4):363-367.

116. Yang L, Wang L, Su XQ, et al. Suppression of ovarian cancer growth via systemic administration with liposome-encapsulated adenovirus-encoding endostatin. Cancer Gene Ther. 2009;17(1): 49-57.

117. Komarova S, Kawakami Y, Stoff-Khalili MA, Curiel DT, Pereboeva L. Mesenchymal progenitor cells as cellular vehicles for delivery of oncolytic adenoviruses. Mol Cancer Ther. 2006;5(3): 755-766.

118. Dembinski JL, Spaeth EL, Fueyo J, et al. Reduction of nontarget infection and systemic toxicity by targeted delivery of conditionally replicating viruses transported in mesenchymal stem cells. Cancer Gene Ther. 2009;17(4):289-297.

119. Fu X, Meng F, Tao L, Jin A, Zhang X. A strict-late viral promoter is a strong tumor-specific promoter in the context of an oncolytic herpes simplex virus. Gene Ther. 2003;10(17):1458-1464.

120. He B, Gross M, Roizman B. The gamma(1)34.5 protein of herpes simplex virus 1 complexes with protein phosphatase 1 alpha to dephosphorylate the alpha subunit of the eukaryotic translation initiation factor 2 and preclude the shutoff of protein synthesis by double-stranded RNA-activated protein kinase. Proc Natl Acad Sci U SA. 1997;94(3):843-848.
121. Sarinella F, Calistri A, Sette P, Palu G, Parolin C. Oncolysis of pancreatic tumour cells by a gamma34.5-deleted HSV-1 does not rely upon Ras-activation, but on the PI 3-kinase pathway. Gene Ther. 2006;13(14):1080-1087.

122. MacLean AR, ul-Fareed M, Robertson L, Harland J, Brown SM. Herpes simplex virus type 1 deletion variants 1714 and 1716 pinpoint neurovirulence-related sequences in Glasgow strain 17+ between immediate early gene 1 and the 'a' sequence. $J$ Gen Virol. 1991;72 (Pt 3):631-639.

123. Coukos G, Makrigiannakis A, Kang EH, et al. Use of carrier cells to deliver a replication-selective herpes simplex virus-1 mutant for the intraperitoneal therapy of epithelial ovarian cancer. Clin Cancer Res. 1999;5(6):1523-1537.

124. Markert JM, Medlock MD, Rabkin SD, et al. Conditionally replicating herpes simplex virus mutant, G207 for the treatment of malignant glioma: results of a phase I trial. Gene Ther. 2000;7(10):867-874.

125. Rampling R, Cruickshank G, Papanastassiou V, et al. Toxicity evaluation of replication-competent herpes simplex virus (ICP 34.5 null mutant 1716) in patients with recurrent malignant glioma. Gene Ther. 2000;7(10):859-866.

126. Fu X, Tao L, Jin A, Vile R, Brenner MK, Zhang X. Expression of a fusogenic membrane glycoprotein by an oncolytic herpes simplex virus potentiates the viral antitumor effect. Mol Ther. 2003;7(6): 748-754

127. Smith CC, Nelson J, Aurelian L, Gober M, Goswami BB. Ras-GAP binding and phosphorylation by herpes simplex virus type 2 RR 1 PK (ICP10) and activation of the Ras/MEK/MAPK mitogenic pathway are required for timely onset of virus growth. $J$ Virol. 2000;74(22):10417-10429.

128. Fujiwara S, Nawa A, Luo C, et al. Carrier cell-based delivery of replication-competent HSV-1 mutants enhances antitumor effect for ovarian cancer. Cancer Gene Ther. 2010;18(2):77-86.

129. Ushijima Y, Luo C, Goshima F, Yamauchi Y, Kimura H, Nishiyama Y. Determination and analysis of the DNA sequence of highly attenuated herpes simplex virus type 1 mutant HF10, a potential oncolytic virus. Microbes Infect. 2007;9(2):142-149.

130. Yoon SS, Carroll NM, Chiocca EA, Tanabe KK. Cancer gene therapy using a replication-competent herpes simplex virus type 1 vector. Ann Surg. 1998;228(3):366-374.

131. Kimata H, Takakuwa H, Goshima F, et al. Effective treatment of disseminated peritoneal colon cancer with new replication-competent herpes simplex viruses. Hepatogastroenterology. 2003;50(52): 961-966.

132. Benencia F, Courreges MC, Conejo-Garcia JR, et al. HSV oncolytic therapy upregulates interferon-inducible chemokines and recruits immune effector cells in ovarian cancer. Mol Ther. 2005;12(5):789-802.

133. McCart JA, Ward JM, Lee J, et al. Systemic cancer therapy with a tumor-selective vaccinia virus mutant lacking thymidine kinase and vaccinia growth factor genes. Cancer Res. 2001;61(24):8751-8757.

134. Thorne SH, Hwang TH, Kirn DH. Vaccinia virus and oncolytic virotherapy of cancer. Curr Opin Mol Ther. 2005;7(4):359-365.

135. Hung CF, Tsai YC, He L, et al. Vaccinia virus preferentially infects and controls human and murine ovarian tumors in mice. Gene Ther 2007;14(1):20-29.

136. Parato KA, Breitbach CJ, Le Boeuf F, et al. The oncolytic poxvirus JX-594 selectively replicates in and destroys cancer cells driven by genetic pathways commonly activated in cancers. Mol Ther. 2012;20(4):749-758.

137. Chalikonda S, Kivlen MH, O’Malley ME, et al. Oncolytic virotherapy for ovarian carcinomatosis using a replication-selective vaccinia virus armed with a yeast cytosine deaminase gene. Cancer Gene Ther. 2008;15(2):115-125.

138. Chang CL, Ma B, Pang X, Wu TC, Hung CF. Treatment with cyclooxygenase-2 inhibitors enables repeated administration of vaccinia virus for control of ovarian cancer. Mol Ther. 2009;17(8): $1365-1372$. 
139. Zhang YQ, Tsai YC, Monie A, Wu TC, Hung CF. Enhancing the therapeutic effect against ovarian cancer through a combination of viral oncolysis and antigen-specific immunotherapy. Mol Ther. 2010;18(4): 692-699.

140. Sypula J, Wang F, Ma Y, Bell J, McFadden G. Myxoma virus tropism in human tumor cells. Gene Ther Mol Biol. 2004;8: 103-114.

141. Wang G, Barrett JW, Stanford M, et al. Infection of human cancer cells with myxoma virus requires Akt activation via interaction with a viral ankyrin-repeat host range factor. Proc Natl Acad Sci U S A. 2006;103(12):4640-4645.

142. Bartee E, McFadden G. Human cancer cells have specifically lost the ability to induce the synergistic state caused by tumor necrosis factor plus interferon-beta. Cytokine. 2009;47(3):199-205.

143. Correa RJ, Komar M, Tong JG, et al. Myxoma virus-mediated oncolysis of ascites-derived human ovarian cancer cells and spheroids is impacted by differential AKT activity. Gynecol Oncol. 2012;125(2):441-450.

144. Peng KW, TenEyck CJ, Galanis E, Kalli KR, Hartmann LC, Russell SJ. Intraperitoneal therapy of ovarian cancer using an engineered measles virus. Cancer Res. 2002;62(16):4656-4662.

145. Anderson BD, Nakamura T, Russell SJ, Peng KW. High CD46 receptor density determines preferential killing of tumor cells by oncolytic measles virus. Cancer Res. 2004;64(14):4919-4926.

146. Mrkic B, Pavlovic J, Rulicke T, et al. Measles virus spread and pathogenesis in genetically modified mice. J Virol. 1998;72(9): $7420-7427$.

147. Myers RM, Greiner SM, Harvey ME, et al. Preclinical pharmacology and toxicology of intravenous MV-NIS, an oncolytic measles virus administered with or without cyclophosphamide. Clin Pharmacol Ther. 2007;82(6):700-710.

148. Bjorge L, Hakulinen J, Wahlstrom T, Matre R, Meri S. Complementregulatory proteins in ovarian malignancies. Int $J$ Cancer. 1997;70(1):14-25.

149. Galanis E, Hartmann LC, Cliby WA, et al. Phase I trial of intraperitoneal administration of an oncolytic measles virus strain engineered to express carcinoembryonic antigen for recurrent ovarian cancer. Cancer Res. 2010;70(3):875-882.

150. Surowiak P, Materna V, Maciejczyk A, et al. CD46 expression is indicative of shorter revival-free survival for ovarian cancer patients. Anticancer Res. 2006;26(6C):4943-4948.

151. Peng KW, Facteau S, Wegman T, O’Kane D, Russell SJ. Non-invasive in vivo monitoring of trackable viruses expressing soluble marker peptides. Nat Med. 2002;8(5):527-531.

152. Peng KW, Hadac EM, Anderson BD, et al. Pharmacokinetics of oncolytic measles virotherapy: eventual equilibrium between virus and tumor in an ovarian cancer xenograft model. Cancer Gene Ther. 2006;13(8):732-738

153. Hasegawa K, Pham L, O’Connor MK, Federspiel MJ, Russell SJ, Peng KW. Dual therapy of ovarian cancer using measles viruses expressing carcinoembryonic antigen and sodium iodide symporter. Clin Cancer Res. 2006;12(6):1868-1875.

154. Myers R, Greiner S, Harvey M, et al. Oncolytic activities of approved mumps and measles vaccines for therapy of ovarian cancer. Cancer Gene Ther. 2005;12(7):593-599.

155. Toffoli G, Cernigoi C, Russo A, Gallo A, Bagnoli M, Boiocchi M. Overexpression of folate binding protein in ovarian cancers. Int $J$ Cancer. 1997;74(2):193-198.

156. Lu Y, Low PS. Immunotherapy of folate receptor-expressing tumors: review of recent advances and future prospects. $J$ Control Release. 2003;91(1-2):17-29.

157. Mader EK, Maeyama Y, Lin Y, et al. Mesenchymal stem cell carriers protect oncolytic measles viruses from antibody neutralization in an orthotopic ovarian cancer therapy model. Clin Cancer Res. 2009;15(23):7246-7255.

158. Thirukkumaran C, Morris DG. Oncolytic viral therapy using reovirus. Methods Mol Biol. 2009;542:607-634.
159. Clarke P, Tyler KL. Down-regulation of cFLIP following reovirus infection sensitizes human ovarian cancer cells to TRAIL-induced apoptosis. Apoptosis. 2007;12(1):211-223.

160. Twigger K, Vidal L, White CL, et al. Enhanced in vitro and in vivo cytotoxicity of combined reovirus and radiotherapy. Clin Cancer Res. 2008;14(3):912-923.

161. Dokianakis DN, Varras MN, Papaefthimiou M, et al. Ras gene activation in malignant cells of human ovarian carcinoma peritoneal fluids. Clin Exp Metastasis. 1999;17(4):293-297.

162. Hirasawa K, Nishikawa SG, Norman KL, Alain T, Kossakowska A, Lee PW. Oncolytic reovirus against ovarian and colon cancer. Cancer Res. 2002;62(6):1696-1701.

163. Fischer U, Schulze-Osthoff K. Apoptosis-based therapies and drug targets. Cell Death Differ. 2005;12 Supp1 1:942-961.

164. Carneiro FA, Bianconi ML, Weissmuller G, Stauffer F, Da Poian AT. Membrane recognition by vesicular stomatitis virus involves enthalpydriven protein-lipid interactions. J Virol. 2002;76(8):3756-3764.

165. Balachandran S, Barber GN. Defective translational control facilitates vesicular stomatitis virus oncolysis. Cancer Cell. 2004;5(1):51-65.

166. Chakraborty P, Seemann J, Mishra RK, et al. Vesicular stomatitis virus inhibits mitotic progression and triggers cell death. EMBO Rep. 2009;10(10):1154-1160.

167. Barber GN. Vesicular stomatitis virus as an oncolytic vector. Viral Immunol. 2004;17(4):516-527.

168. Heiber JF, Xu XX, Barber GN. Potential of vesicular stomatitis virus as an oncolytic therapy for recurrent and drug-resistant ovarian cancer. Chin J Cancer. 2011;30(12):805-814.

169. Capo-chichi CD, Yeasky TM, Heiber JF, Wang Y, Barber GN, $\mathrm{Xu}$ XX. Explicit targeting of transformed cells by VSV in ovarian epithelial tumor-bearing Wv mouse models. Gynecol Oncol. 2009;116(2):269-275.

170. Stojdl DF, Lichty BD, tenOever BR, et al. VSV strains with defects in their ability to shutdown innate immunity are potent systemic anticancer agents. Cancer Cell. 2003;4(4):263-275.

171. Manova K, Nocka K, Besmer P, Bachvarova RF. Gonadal expression of c-kit encoded at the W locus of the mouse. Development. 1990;110(4):1057-1069.

172. Reith AD, Rottapel R, Giddens E, Brady C, Forrester L, Bernstein A. $\mathrm{W}$ mutant mice with mild or severe developmental defects contain distinct point mutations in the kinase domain of the c-kit receptor. Genes Dev. 1990;4(3):390-400.

173. Murphy ED, Beamer WG. Plasma gonadotropin levels during early stages of ovarian tumorigenesis in mice of the $\mathrm{Wx}-\mathrm{Wu}$ genotype. Cancer Res. 1973;33(4):721-723.

174. Brun J, McManus D, Lefebvre C, et al. Identification of genetically modified Maraba virus as an oncolytic rhabdovirus. Mol Ther. 2010;18(8):1440-1449.

175. van den Brule FA, Castronovo V, Menard S, et al. Expression of the $67 \mathrm{kD}$ laminin receptor in human ovarian carcinomas as defined by a monoclonal antibody, MLuC5. Eur J Cancer. 1996;32A(9):1598-1602.

176. Montuori N, Sobel ME. The 67-kDa laminin receptor and tumor progression. Curr Top Microbiol Immunol. 1996;213(Pt 1):205-214.

177. Menard S, Tagliabue E, Colnaghi MI. The $67 \mathrm{kDa}$ laminin receptor as a prognostic factor in human cancer. Breast Cancer Res Treat. 1998;52(1-3):137-145.

178. Huang PY, Guo JH, Hwang LH. Oncolytic Sindbis virus targets tumors defective in the interferon response and induces significant bystander antitumor immunity in vivo. Mol Ther. 2012;20(2):298-305.

179. Tseng JC, Levin B, Hirano T, Yee H, Pampeno C, Meruelo D. In vivo antitumor activity of Sindbis viral vectors. J Natl Cancer Inst. 2002;94(23):1790-1802.

180. Tseng JC, Hurtado A, Yee $\mathrm{H}$, et al. Using sindbis viral vectors for specific detection and suppression of advanced ovarian cancer in animal models. Cancer Res. 2004;64(18):6684-6692.

181. Unno Y, Shino Y, Kondo F, et al. Oncolytic viral therapy for cervical and ovarian cancer cells by Sindbis virus AR339 strain. Clin Cancer Res. 2005;11(12):4553-4560. 
182. Granot T, Venticinque L, Tseng JC, Meruelo D. Activation of cytotoxic and regulatory functions of NK cells by Sindbis viral vectors. PLoS One. 2011;6(6):e20598.

183. Davidson B, Goldberg I, Reich R, et al. AlphaV- and beta1-integrin subunits are commonly expressed in malignant effusions from ovarian carcinoma patients. Gynecol Oncol. 2003;90(2):248-257.

184. Shafren DR, Sylvester D, Johansson ES, Campbell IG, Barry RD. Oncolysis of human ovarian cancers by echovirus type 1. Int J Cancer. 2005;115(2):320-328.

185. Vasey PA, Shulman LN, Campos S, et al. Phase I trial of intraperitoneal injection of the E1B-55-kd-gene-deleted adenovirus ONYX015 (d11520) given on days 1 through 5 every 3 weeks in patients with recurrent/refractory epithelial ovarian cancer. J Clin Oncol. 2002;20(6):1562-1569.

186. Kimball KJ, Preuss MA, Barnes MN, et al. A phase I study of a tropismmodified conditionally replicative adenovirus for recurrent malignant gynecologic diseases. Clin Cancer Res. 2010;16(21):5277-5287.

187. Breitbach CJ, Burke J, Jonker D, et al. Intravenous delivery of a multimechanistic cancer-targeted oncolytic poxvirus in humans. Nature. 2011;477(7362):99-102.

188. Cerullo V, Pesonen S, Diaconu I, et al. Oncolytic adenovirus coding for granulocyte macrophage colony-stimulating factor induces antitumoral immunity in cancer patients. Cancer Res. 2010;70(11): 4297-4309.

189. Koski A, Kangasniemi L, Escutenaire S, et al. Treatment of cancer patients with a serotype $5 / 3$ chimeric oncolytic adenovirus expressing GMCSF. Mol Ther. 2010;18(10):1874-1884.

190. Yin BW, Lloyd KO. Molecular cloning of the CA125 ovarian cancer antigen: identification as a new mucin, MUC16. J Biol Chem. 2001;276(29):27371-27375.

191. Vanderplasschen A, Mathew E, Hollinshead M, Sim RB, Smith GL. Extracellular enveloped vaccinia virus is resistant to complement because of incorporation of host complement control proteins into its envelope. Proc Natl Acad Sci U S A. 1998;95(13):7544-7549.
192. Zhang Q, Yu YA, Wang E, et al. Eradication of solid human breast tumors in nude mice with an intravenously injected light-emitting oncolytic vaccinia virus. Cancer Res. 2007;67(20):10038-10046.

193. ClinicalTrials.gov. A study of GL-ONC1, an oncolytic vaccinia virus, in patients with advanced peritoneal carcinomatosis. Available from: http://www.clinicaltrials.gov/ct2/show/NCT01443260?term=GLONC1\&rank=1. Accessed July 23, 2012.

194. ClinicalTrials.gov. Viral therapy in treating patients with ovarian epithelial cancer, primary peritoneal cancer, or fallopian tube cancer that did not respond to platinum chemotherapy. Available from: http:// www.clinicaltrials.gov/ct2/show/NCT00602277?term=Reolysin\&ran $\mathrm{k}=14$. Accessed July 23, 2012.

195. ClinicalTrials.gov. Paclitaxel with or without viral therapy in treating patients with recurrent or persistent ovarian epithelial, fallopian tube, or primary peritoneal cancer. Available from: http://www.clinicaltrials. gov/ct2/show/NCT01199263?term=Reolysin\&rank=15. Accessed July 23, 2012.

196. Phelps MA, Cohn DE, O’Malley DM, et al. Reovirus replication in ovarian and peritoneal tumors after intravenous administration. In: Proceedings of the 101st Annual Meeting of the American Association for Cancer Research; April 17-21, 2010; Washington, DC. Philadelphia: AACR; 2010.

197. Kelly E, Russell SJ. History of oncolytic viruses: genesis to genetic engineering. Mol Ther. 2007;15(4):651-659.

198. Garber K. China approves world's first oncolytic virus therapy for cancer treatment. J Natl Cancer Inst. 2006;98(5):298-300.

199. Preston CC, Goode EL, Hartmann LC, Kalli KR, Knutson KL. Immunity and immune suppression in human ovarian cancer. Immunotherapy. 2011;3(4):539-556.

200. Young DF, Galiano MC, Lemon K, et al. Mumps virus Enders strain is sensitive to interferon (IFN) despite encoding a functional IFN antagonist. J Gen Virol. 2009;90(Pt 11):2731-2738.

201. Rotbart HA. Antiviral therapy for enteroviruses and rhinoviruses Antivir Chem Chemother. 2000;11(4):261-271.
Oncolytic Virotherapy

\section{Publish your work in this journal}

Oncolytic Virotherapy is an international, peer-reviewed, open access online journal publishing original research, study protocols, reviews, editorials and commentaries on all aspects of oncolytic virology, namely the application of oncolytic viruses for the treatment of cancer. Specific topics in the journal include: Rationale and theoretical aspects of oncolytic virotherapy including in vitro, in vivo and mathematical

Submit your manuscript here: http://www.dovepress.com/oncolytic-virotherapy-journal

\section{Dovepress}

modeling; and practical application and problem solving in the clinic including identification of potential responders through biomarkers and genetic profiling. The manuscript management system is completely online and includes a very quick and fair peer-review system, which is all easy to use. Visit http://www.dovepress.com/ testimonials.php to read real quotes from published authors. 